\title{
SUBPREDICAÇÃO \\ E SMALL CLAUSE NA \\ SINTAXE MAIS SIMPLES: \\ UM CASO DE NÃO \\ -UNIFORMIDADE \\ NA INTERFACE
}

\section{SUBPREDICACIÓN Y SMALL CLAUSE EN LA SINTAXIS MÁS SIMPLE: UN CASO DE NO UNIFORMIDAD EN LA INTERFAZ}

\author{
SUBPREDICATION AND SMALL CLAUSE IN SIMPLER SYNTAX: A CASE OF NON- \\ UNIFORMITY AT THE INTERFACE
}

Rafaela Miliorini*

Heronides Moura**

Universidade Federal de Santa Catarina

RESUMO: Esta pesquisa analisa o fenômeno semântico da subpredicação a partir da Teoria da Sintaxe mais Simples (SMS) (CULICOVER; JACKENDOFF, 2005). Nessa abordagem, uma vez que a semântica é gerada paralelamente, é proposta a nãouniformidade de interface como opção de economia teórica: a estrutura sintática é reduzida, projetando somente os itens pronunciados. Analisamos sentenças com verbos que selecionam subpredicação e aplicamos testes de constituência para verificar em quais casos esses verbos licenciam um único constituinte sintático como complemento. Nos casos em que é atestada a formação de constituinte, a subpredicação é projetada sintaticamente como uma small clause (SC); nos demais, a relação de predicação ocorre diretamente com o verbo e não é formada uma SC - para esses verbos, a representação sintática é semelhante à projeção de verbos triargumentais. Os resultados mostraram que muitos verbos tradicionalmente considerados selecionadores de SC não o são, embora estabeleçam relação de subpredicação no nível semântico.

PALAVRAS-CHAVE: Subpredicação. Small clause. Sintaxe mais Simples. Uniformidade de Interface.

RESUMEN: En esta investigación se analiza el fenómeno semántico de la subpredicación a partir de la Teoría de la Sintaxis más Simple (SMS) (CULICOVER; JACKENDOFF, 2005). Se propone, en este enfoque, puesto que la semántica se genera paralelamente, la no uniformidad de interfaz como opción de economía teórica: la estructura sintáctica se reduce, proyectando solamente las

\footnotetext{
* Doutoranda do Programa de Pós-graduação em Linguística da Universidade Federal de Santa Catarina. E-mail: rafaelamiliorini@gmail.com.

** Doutor em Linguística pela Unicamp. Professor titular da Universidade Federal de Santa Catarina. Pesquisador do CNPq. Presidente da ANPOLL (2012-2014) e coordenador da Pós-graduação em Linguística da UFSC (2010-2014). Email: heronides.moura@ufsc.br.
} 
unidades/los elementos que se pronuncian. Analizamos enunciados con verbos que requieren subpredicación y realizamos pruebas de constituyentes para verificar en qué situaciones esos verbos permiten un único constituyente sintáctico como complemento. En los casos en los cuales se comprueba la formación de constituyente, la subpredicación se proyecta sintácticamente como una small clause (SC); en los demás, la relación de predicación ocurre directamente con el verbo y no se compone una SC - en esos verbos la representación sintáctica se parece a la proyección de verbos triargumentales. Los resultados demostraron que muchos verbos tradicionalmente tratados como seleccionadores de SC no lo son, aunque establezcan una relación de subpredicación a nivel semántico.

PALABRAS CLAVE: Subpredicación. Small clause. Sintaxis más Simple. Uniformidad de Interfaz.

ABSTRACT: This research analyzes the semantic phenomena of subpredication based on Simpler Syntax (CULICOVER; JACKENDOFF, 2005). In their proposal, once semantics is generated in parallel, we have a presumption of non-uniformity as an option for theoretical economy: syntactic structures are maximally reduced, projecting only pronounced elements. We analyzed sentences containing verbs that select for subpredications and applied constituency tests in order to verify in which of these cases the verbs license an unique syntactic constituent as complement. Where we do attest the formation of such a constituent, the subpredication is syntactically projected as a small clause (SC); in all other cases, predication relations are set up directly with the verb, and no SC is formed - for this group of verbs, the syntactic representation is similar to that of double object verbs. Our results revealed that many verbs traditionally considered to select SCs, in fact, don't do so, even though they establish a subpredication relation on the semantic level.

KEYWORDS: Subpredication. Small clause. Simpler Syntax. Interface Uniformity.

\section{INTRODUÇÃO}

Este estudo pretende analisar as possibilidades de estruturação sintática do fenômeno semântico da subpredicação em português brasileiro (PB), a partir da Teoria da Sintaxe mais Simples (SMS) de Culicover e Jackendoff (2005). Será importante para a presente análise a discussão sobre a (não-)uniformidade na interface entre sintaxe e semântica (MOURA, 2018).

O fenômeno que investigamos pode ser compreendido como uma predicação interna a outra predicação:

(1) Helena viu Sarah.

(2) Helena viu Sarah correndo.

Na sentença (1), há a estrutura de predicação $x$ ver $y$, com os dois espaços argumentais sendo preenchidos por Helena e Sarah. A sentença (2) é aparentemente estruturada em $x$ ver $y z$, contendo três espaços argumentais; entretanto, $y$ e $z$ são, na verdade, subdivisões de um mesmo constituinte semântico, o qual forma uma segunda predicação, interna à primeira. Portanto, a estrutura presente em (2) é $\boldsymbol{x}$ ver $\boldsymbol{s}$, onde $\mathrm{x}=$ Helena e s $=$ Sarah correndo.

(2’) Helena [viu [Sarah correndo]].

Ao saturarmos a variável s com Sarah correndo, é formado o predicado viu Sarah correndo (que atribui à Helena a propriedade de ter visto Sarah correndo) e o predicado correndo (que atribui à Sarah a propriedade de correr). Vamos chamar a primeira relação de predicação principal e a segunda de subpredicação - i.e., uma predicação interna à outra.

Para a Gramática Gerativa Tradicional (doravante GGT) ${ }^{1}$, o que estamos chamando aqui de subpredicação é um fenômeno usualmente projetado na sintaxe como uma small clause (SC), termo introduzido por Williams (1975) para denominar um tipo específico de construção linguística que expressa relação entre sujeito e predicado. Esse conceito é contrastado com o de sentença

\footnotetext{
${ }^{1}$ Seguindo Culicover e Jackendoff (2005), utilizaremos o termo Gramática Gerativa Tradicional (GGT) para denominar a linha de pesquisa da Gramática Gerativa mais diretamente associada a Noam Chomsky (1957, 1965, 1972, 1975, 1981, 1993, 1995).
} 
plena (full clause), pois, no caso específico das SCs, a predicação não ocorre através de um verbo flexionado, mas de um adjetivo, preposição, nome ou verbo não-flexionado. Os estudos acerca das SCs se consolidaram com os trabalhos de Chomsky (1981) e Stowell (1983) e ainda hoje constituem um campo produtivo de investigação dentro da GGT.

(3) Helena julgou [sc [NP Sarah] [AP inconsequente]]

(4) Helena imaginou [sc [Np Sarah] [pp na praia]]

(5) Helena considera [sc [Np Sarah] [Np um doce]]

O exemplo (1) exprime uma predicação através de sentença plena (full clause), com o verbo ver flexionado. Nas sentenças (2), (3), (4) e (5) temos exemplos de SCs com predicação por meio de um sintagma gerundivo, um adjetival, um preposicionado e um nominal, respectivamente. Cada um desses casos é também um exemplo de sentença plena, pois todos apresentam um verbo principal flexionado que encarna a predicação principal. Em (3), por exemplo, o verbo julgar contém a predicação principal: atribui à Helena a propriedade de julgar Sarah inconsequente; na mesma construção, a subpredicação ocorre através do adjetivo inconsequente, que atribui à Sarah a propriedade de ser inconsequente. O mesmo acontece com os demais exemplos.

De acordo com Culicover e Jackendoff (2005), esse tratamento tradicional dado ao fenômeno das SCs é decorrente da obrigatoriedade, dentro da teoria, de tratar sintaxe e semântica como componentes que projetam estruturas unívocas. Na GGT (CHOMSKY, 1965; 1981; 1995), a sintaxe é tomada como a fonte central e única da geração linguística, a partir da qual tanto a fonologia quanto a semântica são estruturadas. Há, portanto, uma presumida uniformidade entre forma e sentido: cada projeção semântica é derivada de uma estrutura sintática subjacente e para cada estrutura sintática deve haver apenas uma estrutura semântica correspondente. A relação é, portanto, de um para um (MOURA, 2018). Portanto, dado que uma predicação exprime uma proposição completa e que predicações normalmente são expressas por constituintes sentenciais, se temos uma predicação semântica, deveríamos ter, analogamente, uma projeção sentencial na estrutura sintática.

Contrariamente, Culicover e Jackendoff (2005) sustentam, à luz da SMS, que apenas algumas estruturas de subpredicação (que os autores chamam de NP-Pred) formam SCs - outros casos de subpredicação teriam representações sintáticas distintas. Eles apresentam algumas evidências que apontam a favor da estruturação canônica das SCs, mas afirmam que em muitos casos - na maioria das estruturas analisadas como SCs pela GGT - não há indícios para a formação desse sintagma e a estrutura seria, portanto, flat (plana).

Neste artigo, pretendemos mapear quais são as projeções sintáticas da subpredicação, de acordo com o verbo que as seleciona. Para tanto, aplicamos testes tradicionais de constituência para verificar quais verbos, dentre aqueles que selecionam semanticamente uma subpredicação, realmente podem subcategorizar um constituinte do tipo SC.

Visto que a SMS prevê uma "arquitetura em paralelo" para a linguagem, estabelecida sobre três eixos gerativos relativamente autônomos (fonologia, sintaxe e semântica), fenômenos linguísticos anteriormente subsumidos à teoria sintática podem ser repartidos entre os outros componentes da gramática. Apoiando-nos nessa teoria, acreditamos que o fenômeno da subpredicação pode ser representado sintaticamente de forma mais parcimoniosa. Colocamos em questão que todos os casos de subpredicação precisem receber uma representação uniforme como SCs. Tentaremos mostrar que a aplicação de testes de constituência em alguns dados do PB apontam para um resultado híbrido: algumas estruturas de subpredicação, (tradicionalmente consideradas SCs) realmente são small clauses sintáticas, mas outras realizam a predicação diretamente com o verbo, não projetando um sintagma sentencial autônomo.

Ademais, com este estudo, tomando como fundamento a teoria de Culicover e Jackendoff (2005), buscamos explorar a nãoobrigatoriedade de uniformidade entre forma e sentido na língua, hipotetizando que a relação sintaxe-semântica pode não ser isomórfica. Isso nos levará a propor uma projeção alternativa para instâncias de subpredicação que, de acordo com nossa análise, não formam constituintes sentenciais e que, portanto, não apresentam as mesmas regras de correspondência das SCs. Como temos estruturas sintáticas diferentes - algumas vezes com formação de SCs e outras não - para o mesmo fenômeno semântico (a 
subpredicação), as regras que estabelecem a interface entre esses dois níveis não podem permanecer uniformes. Uma mesma relação semântica de predicação poderá ser codificada por vários tipos de construções sintáticas (sentenças inteiras, SCs e as estruturas que Culicover e Jackendoff chamam de falsas SCs).

\section{DEFININDO O OBJETO: A SUBPREDICAÇÃO}

Como dissemos na introdução, o que chamamos neste trabalho de subpredicação pode ser entendido como uma predicação interna a outra. Vejamos os seguintes exemplos:

(6) Ana trabalha.

(7) Ana cantou o hino

Na sentença (6), há um predicado monoargumental, o verbo inergativo trabalhar, sendo preenchido pelo argumento Ana. Na sentença (7), podemos tanto considerar que há novamente um predicado monoargumental, cantar o hino, sendo preenchido pelo argumento Ana, quanto decompor esse predicado em unidades menores, obtendo um predicado biargumental, cantar, com os espaços argumentais sendo ocupados por Ana e o hino.

Do mesmo modo, as proposições em (8a) e (9a) podem ser analisadas como formadas a partir de predicados monovalentes:

(8) a. Ana colocou o carro na garagem.

b. x colocar o carro na garagem.

(9) a. A juíza julgou Pedro culpado.

b. x julgar Pedro culpado

Em (8b) e em (9b) temos uma predicação principal, e, em (8a) e (9a), a variável x é saturada pelos argumentos Ana e a juíza, respectivamente. Podemos, todavia, decompor esses predicados em unidades menores e obter uma estrutura diferente:

(8) c. x colocar y em $z$

(9) c. x julgar y z

Os predicados são, agora, aparentemente triargumentais: o predicado em (8c) é $x$ colocar $y$ em $z$, onde $\mathrm{x}=\mathrm{Ana} ; \mathrm{y}=\mathrm{o}$ carro; $\mathrm{z}=$ garagem. Em (9c), o predicado é $x$ julgar $y z$, onde $\mathrm{x}=$ a juíza; $\mathrm{y}=$ Pedro; $\mathrm{z}$ = culpado. Definiremos aqui que, nas duas estruturas, $\mathrm{x}$ é o argumento externo à predicação principal e y e z são argumentos internos a ela. A diferença entre as duas estruturas está no fato de a segunda conter uma outra predicação, interna à principal, ou seja, em (9), x julgar Pedro culpado é a predicação principal e Pedro culpado é a predicação interna, ou subpredicação. Nesses casos, $y$ e $z$ (definidos acima como argumentos internos) são, na verdade, partes de um único constituinte semântico. Teríamos, portanto, uma estrutura do tipo x julgar s.

Na predicação principal, de acordo com a terminologia de Searle (1969), o predicado julgar Pedro culpado atribui à juíza a propriedade de julgar Pedro culpado; na subpredicação, o predicado culpado atribui a Pedro a propriedade de ser culpado. Sendo assim, a subpredicação ocorre quando, internamente a uma predicação, há, adicionalmente, a atribuição de uma propriedade a um indivíduo.

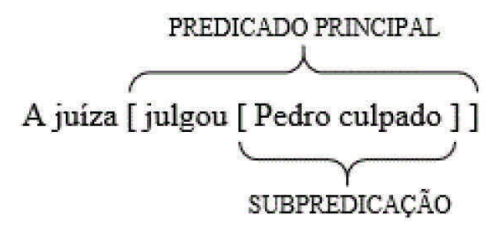

Diagrama 1: Predicado principal e subpredicação 
Como as sentenças codificam semanticamente proposições completas, elas expressam também, invariavelmente, relações predicativas. Isso significa, contudo, que uma relação semântica não-predicativa não pode ser expressa por uma sentença. Esse dado sugere um teste para identificar a subpredicação: se conseguirmos parafrasear uma sentença com um predicado triargumental substituindo os dois argumentos internos à sua predicação principal ( $y$ e $z$, reformulados como $s$ ) por uma sentença encaixada, temos uma subpredicação. Caso a paráfrase não seja aceitável, temos um indício de que os dois argumentos internos não formam uma outra predicação, mas expressam outro tipo de relação semântica.

(8) d. *Ana colocou que o carro está na garagem / o carro quando ele está na garagem.

(9) d. A juíza julgou que Pedro é culpado.

Quando tentamos parafrasear Ana colocou o carro na garagem em (8d), a sentença resultante é agramatical, pois a relação entre $o$ carro e na garagem não é predicativa. Já em (9d) o teste funciona, evidenciando que Pedro culpado de fato forma uma subpredicação.

Temos, portanto:

(10) a. Ana viu Pedro dançando.

b. Ana viu Pedro quando ele estava dançando.

(11) a. Ana imaginou Pedro em sua casa.

b. Ana imaginou que Pedro estava na sua casa.

(12) a. Ana considera Pedro criativo.

b. Ana considera que Pedro é criativo.

(13) a. Ana encontrou Pedro triste.

b. Ana encontrou Pedro quando ele estava triste. ${ }^{2}$

(14) a. Ana quer o filho de banho tomado.

b. Ana quer que o filho esteja de banho tomado.

(15) a. Ana ouviu Pedro chorando.

b. Ana ouviu que Pedro estava chorando.

(16) a. Ana declarou encerrada a solenidade.

b. Ana declarou que a solenidade está encerrada.

(17) a. Ana esperava uma noite mais agradável.

b. Ana esperava que a noite fosse mais agradável.

(18) a. Ana sentiu o cachorro deitando no seu pé.

b. Ana sentiu que o cachorro estava deitando no seu pé.

(19) a. Ana visualizou o apartamento mobiliado.

b. Ana visualizou que o apartamento estava mobiliado.

\footnotetext{
${ }^{2}$ A subpredicação associada ao verbo encontrar é projetada sintaticamente, em X-barra (GGT), como uma small clause adjunto, não complemento, como nas sentenças supracitadas. Todavia, na SMS não há diferença entre a projeção sintática de argumentos e de adjuntos no componente sintagmático - essa distinção é formalizada apenas na Camada de Funções Gramaticais (subnível sintático) e na estrutura semântica. Voltaremos a essa questão na seção 5 . O que estamos analisando, contudo, é um fenômeno caracterizado semanticamente, não sintaticamente.
} 
Mas não:
a. Ana emprestou o livro a Pedro.
b. ${ }^{\star}$ Ana emprestou que o livro é Pedro / quando o livro estava com Pedro

a. Ana doou as roupas para o abrigo.

b. ${ }^{\star A n a ~ d o o u ~ q u e ~ a s ~ r o u p a s ~ s a ̃ o ~ d o ~ a b r i g o ~ / ~ q u a n d o ~ a s ~ r o u p a s ~ e s t a v a m ~ n o ~ a b r i g o ~}$

Os exemplos acima mostram que os verbos das sentenças (9) a (19) podem selecionar semanticamente uma subpredicação, o que não ocorre com os verbos dos exemplos $(8),(20)$ e $(21)^{3}$.

A definição de subpredicação que propusemos parece ser aplicável também a verbos como proclamar, pensar, eleger e nomear, pois eles aparentam possuir uma predicação interna a outra:

(22) a. Marechal Deodoro proclamou o Brasil uma República.

Em (22), temos a predicação principal, proclamar o Brasil uma República, e uma outra atribuição de um predicado a um objeto, uma subpredicação, o Brasil uma República. Entretanto, esses verbos não passam no teste da maneira como ele foi aplicado aos exemplos anteriores:

(22) b. ? Marechal Deodoro proclamou que o Brasilé uma República.

(23) a. O reitor pensava em uma universidade mais segura.

b. ? O reitor pensava que a universidade era mais segura.

(24) a. O Brasil elegeu Dilma presidente.

b. ? O Brasil elegeu que Dilma é presidente.

(25) a. Temer nomeou Cristiane Brasil ministra do Trabalho.

b. ? Temer nomeou que Cristiane Brasilé ministra do Trabalho.

As sentenças resultantes (22b), (23b), (24b) e (25b) são um pouco estranhas. No caso das paráfrases com os verbos proclamar e pensar, a sentença resultante exprime outro significado: proclamar que o Brasil é uma República possui a acepção assertiva e não declarativa de proclamar, nos termos de Searle (1979)4. Proclamar o Brasil uma República descreve uma declaração - i.e. um ato de fala que cria um novo estado de coisas no mundo; já Proclamar que o Brasil é uma República descreve uma asserção - i.e. uma mera constatação de um estado de coisas previamente existente. Algo semelhante acontece com o exemplo (23): (23a) tem uma leitura imaginativa, e (23b) não. Na primeira, o verbo pensar apresenta a ideia de algo que foi imaginado pelo sujeito, como a projeção de uma possibilidade futura; já na segunda, a interpretação traduz uma espécie de quebra de expectativa: o reitor supunha algo que se mostrou falso na realidade ${ }^{5}$.

\footnotetext{
${ }^{3}$ Um resultado bem-sucedido decorrente da aplicação do teste não requer que as sentenças resultantes da paráfrase (através de sentenças encaixadas) sejam sinônimos perfeitos das sentenças originais. Veja que nos exemplos em que o teste não funciona, com os verbos colocar, emprestar e doar, não conseguimos sequer elaborar uma paráfrase sentencial minimamente aceitável.

${ }^{4}$ O que Searle (1979) chama de declaração é semelhante ao que Austin (1962) denominou ato de fala performativo.

${ }^{5}$ Sobre verbos com interpretação imaginativa, cf. Rodrigues (2004).
} 
Nas sentenças com os verbos eleger e nomear ((24) e (25)), as paráfrases resultantes são sintaticamente anômalas. Mas poderíamos manipular essas sentenças de forma a preservar a aceitabilidade se substituíssemos a sequência testada por uma construção com verbo no infinitivo:

$$
\text { c. O Brasil elegeu Dilma para ser presidente. }
$$

c. Temer nomeou Cristiane Brasil para ser ministra do Trabalho.

Entretanto, essa paráfrase não garante uma relação predicativa, pois não é uma sentença (não possui núcleo de flexão temporal):

(24) d.

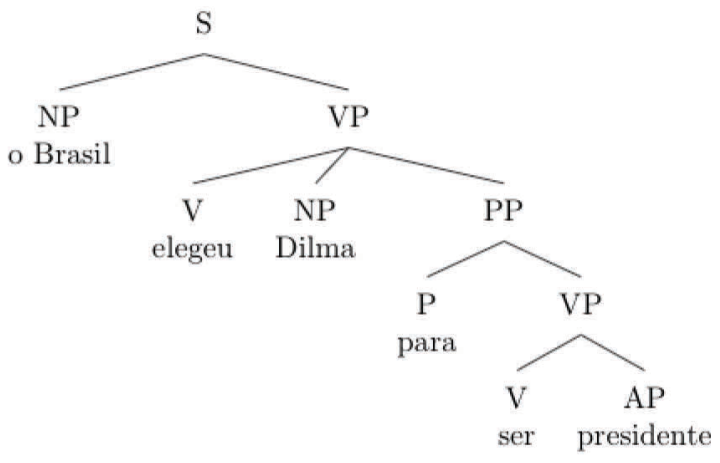

O teste por nós sugerido é o de paráfrase por sentença encaixada, pois essa é a forma de assegurar a categoria semântica da sequência testada. A paráfrase, portanto, deve ter a seguinte estrutura (onde o S dominado por VP é uma sentença encaixada e Comp é a posição do complementizador):

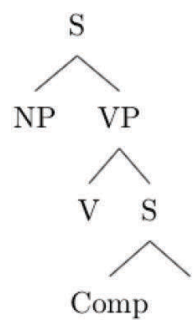

As sentenças resultantes em (22b), (23b), (24b) e (25b), mesmo que sejam sintaticamente anômalas (ou não exprimam um sentido idêntico ao da sentença original), funcionam como testes para a verificação da existência de uma relação predicativa, pois, ao contrário dos exemplos (8), (20) e (21), nenhuma dessas sentenças é patentemente agramatical. Por essa razão, trataremos, na análise de dados deste artigo, os verbos proclamar, pensar eleger e nomear, juntamente com os citados nas sentenças de (9) a (19), como selecionadores de subpredicação. 


\title{
3 A PROPOSTA TRADICIONAL DE REPRESENTAÇÃO SINTÁTICA PARA A SUBPREDICAÇÃO: AS SCS
}

\author{
3.1 CARACTERÍSTICAS GERAIS
}

A GGT adota uma única representação sintática para todos os casos de subpredicação na semântica: a small clause. Os estudos acerca dessa estrutura sintática têm início com Williams (1975; 1983), mas, dentro da tradição gerativa, seguem, em linhas gerais, a proposta de Chomsky (1981) e de Stowell (1983). Segundo essa abordagem, as chamadas small clauses são estruturas sintáticas uniformes, que se projetam invariavelmente da seguinte forma:

(27)

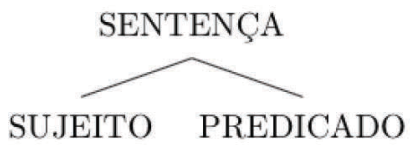

As SCs expressam, pois, uma relação de predicação entre uma expressão referencial (geralmente um NP) e um predicado não-verbal (sem flexão). Em uma sentença como Ana achou o rapaz alegre, na posição de sujeito da SC, temos o rapaz e na de predicado, alegre:

(28)

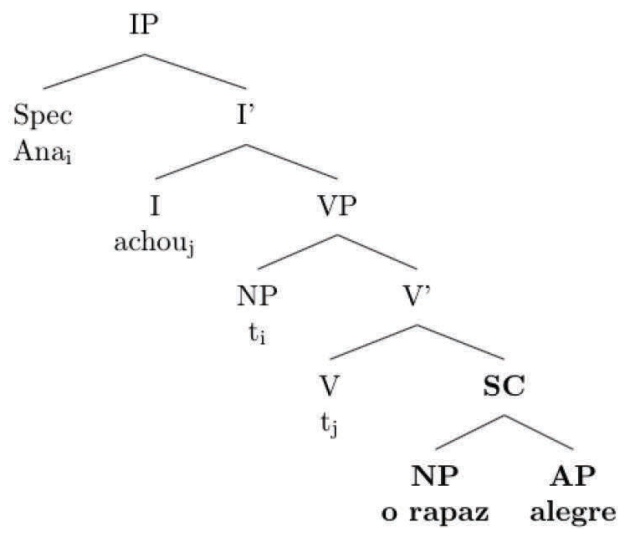

Na estrutura em (28), achar é tomado como sinônimo de considerar. Nessa acepção, seu complemento exprime uma relação predicativa, formando uma small clause na sintaxe. Mas o complemento desse verbo pode assumir também uma leitura referencial não-predicativa, e, portanto, não ser projetado como uma SC: [o rapaz alegre] seria projetado apenas como um NP:

(29)

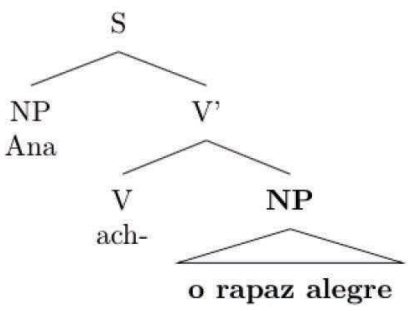


Como notam Mioto e Foltran (2007, p. 15), as SCs podem funcionar como uma espécie de abreviação de sentenças circunstanciais, como em (30), ou de descritivas, como em (31):

(30) a. João comeu a carne crua.

b. João comeu a carne enquanto estava crua.

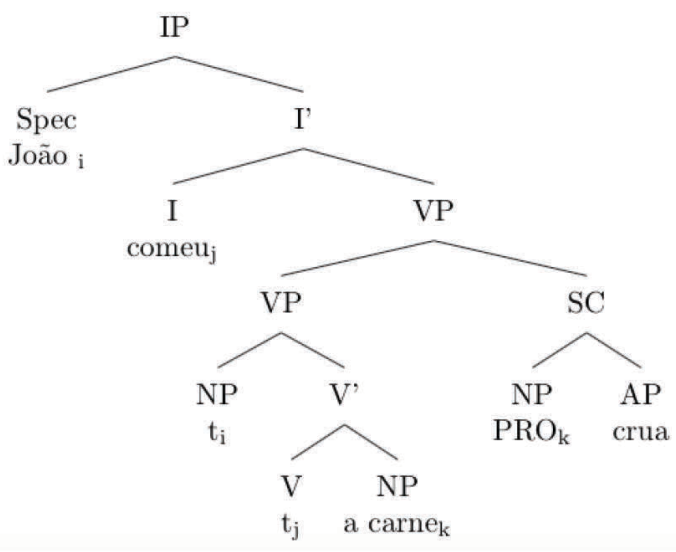

(31) a. João comprou as cenouras frescas.

b. João comprou as cenouras, que estavam frescas.

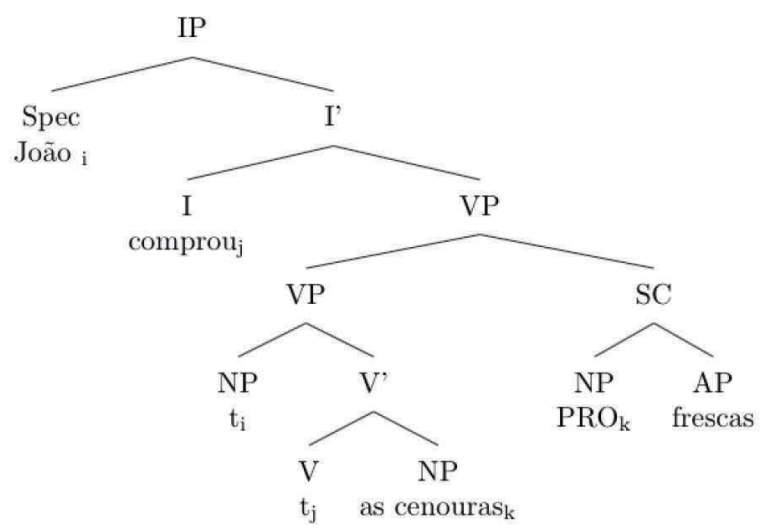

De acordo com os autores, as SCs podem ocorrer em duas funções gramaticais distintas: (i) complemento de VP, como em (28), em que a SC aparece como argumento interno do verbo achar, ou (ii) adjunto de VP, como em (30) e (31), em que a SC codifica predicados circunstanciais ou descritivos.

\subsection{ESTRUTURA INTERNA}

Como descrito acima, as SCs são estruturas formadas por uma combinação entre sujeito e predicado. Segundo Mioto e Foltran (2007), na posição sujeito das SCs, podem figurar DPs (NPs), InfPs e CPs; na posição predicado, APs, DPs (NPs), PPs e VPs (estes podem ser InfPs, GerPs ou PartPs - mas nunca IPs). Nos dados supracitados, mostramos apenas SCs que selecionam como sujeito um NP e como predicado um AP.

Contreras (1995) propõe uma reclassificação das SCs de acordo com o tipo de predicado que elas contêm, repartindo-as em dois grandes grupos: $[+\mathrm{V}]$ e $[-\mathrm{V}]$. No primeiro grupo estão as que apresentam predicados adjetivais (APs) ou verbais (VPs); no segundo, 
as que projetam predicados nominais $(\mathrm{NPs})^{6}$ ou preposicionais (PPs). Teríamos, pois, (32a,b) como representativas do grupo [+V] e (32c,d), do grupo $[-V]$.

(32) a. Ana quer [sc [NP Maria] [Ap contente]].

b. Ana viu [sc [Np Maria] [vp lendo]].

c. Ana considera [sc [Np Maria] [np uma ótima professora]].

d. Ana parece [sc [NP $\left.\mathrm{PRO}_{\mathrm{i}}\right]$ [pp de açúcar].

Nos estudos iniciais sobre o fenômeno (cf. STOWELL, 1983), propunha-se que a ausência de categorias funcionais (e presença exclusiva de categorias lexicais) seria a principal diferença entre small clauses e full clauses. As SCs, portanto, não apresentariam núcleo flexional I, o que as tornaria dependentes de sentenças plenas, podendo figurar apenas sob a regência da flexão da sentença matriz - que definiria, consequentemente, o tempo da SC. Por essa razão, os fragmentos abaixo não seriam gerados na gramática do adulto ${ }^{7}$ :
a. ${ }^{*}$ SC [NP Maria] [AP contente]].
b. ${ }^{*}[\mathrm{sC}[\mathrm{NP}$ Maria] [vp lendo]].
c. ${ }^{*}[\mathrm{SC}$ [NP Maria] [NP uma ótima professora]].
d. *[sc [Np Ana] [pp de açúcar].

Todavia, diversos trabalhos posteriores (cf. RAPOSO; URIAGEREKA, 1990; CHOMSKY, 1991; CINQUE, 1991; CARDINALETTI; GUASTI, 1992; HAEGEMAN, 1994, entre outros) defendem a existência de projeções funcionais dentro das SCs. A posição desses autores fundamenta-se em dados de línguas como o português, o italiano e o francês, que realizam a concordância de número e gênero entre o nome e o adjetivo, como nos exemplos em (34):

(34) a. Márcia considera o aluno muito esperto.

b. Márcia considera a aluna muito esperta [FEM].

c. Márcia considera os alunos muito espertos [PL].

d. Márcia considera as alunas muito espertas $[\mathrm{FEM}-\mathrm{PL}]^{8}$.

Embora as estruturas acima não comportem uma flexão de núcleo I (assumindo que de fato as SCs não projetam sentenças plenas), Haegeman (1994) e Cardinaletti e Guasti (1995) argumentam que a flexão morfológica número-pessoal - presente em casos como (34) - estaria projetada em um núcleo (funcional) Agr, que sinaliza a concordância:

b’

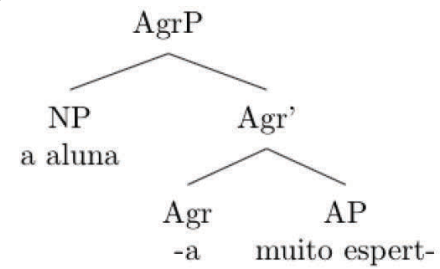

\footnotetext{
${ }^{6}$ Para Cardinaletti e Guasti (1995), os predicados nominais sempre veiculam propriedades do tipo individual-level, ou seja, propriedades inerentes e permanentes dos indivíduos, como alto, inteligente etc. Para maior discussão acerca da distinção entre adjetivos individual level e stage level nas small clauses, cf. Raposo e Uriagereka (1995), Foltran (1999) e Mioto e Foltran (2007).

${ }^{7}$ Essas sequências são tratadas por Stowell (1983) e outros autores como fragmentos sentenciais, agramaticais na língua dos adultos. Entretanto, estudos subsequentes (cf. Radford (1990) e Progovac (2015)) frisaram que, além de cumprirem um papel relevante na gramática das crianças, tais estruturas - chamadas de "small clauses raiz" - podem ser geradas pela gramática do adulto em contextos conversacionais específicos.

${ }^{8}$ Os exemplos em (8) são foram adaptados de Haegeman (1994, p. 125).
} 
Guéron e Hoekstra (1995) também defendem que small clauses e full clauses se distinguem pelo fato de as primeiras não disporem de núcleo I. Entretanto, afirmam que as SCs sempre possuem projeção Agr. Para Contreras (1995), o sujeito da SC do grupo [+V] c-comanda o predicado, movendo-se para uma posição mais alta, no especificador de uma projeção funcional F qualquer:

(35) Ele considera [Maria inteligente]

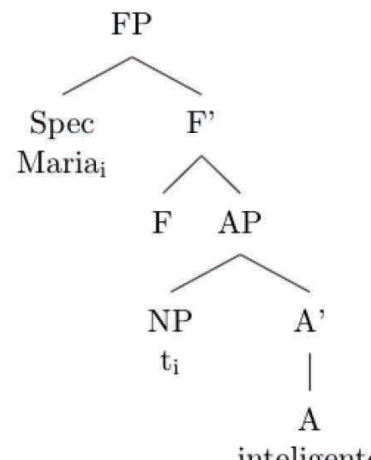

A despeito desses argumentos, há estudos ainda mais recentes que continuam assumindo a proposta pioneira de Stowell (1983; 1995) (cf. ROTHSTEIN, 1995; PROGOVAC, 2006; MIOTO; FIGUEIREDO SILVA; LOPES, 2007; MIOTO; FOLTRAN, 2007; GOMES; FOLTRAN, 2009; KATO; MIOTO, 2015, entre outros). Chomsky (1995, p. 325), já no programa minimalista, afirma que "Para small clauses, nós temos algo como as suposições originais de Stowell (1978), sobre as quais boa parte do trabalho recente se baseou [...]".

De acordo com Stowell (1995), o que distingue as SCs das sentenças plenas é, basicamente, a ausência de verbos auxiliares ou de morfologia de tempo/aspecto nas primeiras - embora os sujeitos de SCs possam também desencadear concordância de gênero e número. Há, por outro lado, uma semelhança mais profunda entre esses dois tipos de estrutura: ambas codificam a mesma relação semântica de predicação. Por isso, Stowell (1995) considera que ambas instanciam um mesmo esquema geral de representação "sentencial", onde:

(36) Sentença: IP

Sujeito: NP

Predicado: PredP, VP

Haveria, portanto, a seguinte correlação:

\begin{tabular}{l|l} 
Small clause & Full clause \\
\hline SUJEITO PREDICADO & Quadro 1: Correlação entre a estrutura sentencial de small clauses e full clauses (STOWELL, 1995, p.272)
\end{tabular}

Há, de fato, concordância número-pessoal em casos como (34). Entretanto, postular a existência de projeções funcionais dentro dessas estruturas configura mais um passo na direção da complexificação estrutural de um fenômeno que talvez possa ser representado como sintaticamente mais simples, ainda que comporte um valor semântico completo, equivalente ao das sentenças plenas. Vejamos, então, qual alternativa Culicover e Jackendoff (2005) oferecem às propostas anteriormente discutidas. 


\title{
4 UMA VISÃO ALTERNATIVA: O TRATAMENTO DA SUBPREDICAÇÃO NA SINTAXE MAIS SIMPLES
}

\author{
4.1 PRESSUPOSTOS GERAIS
}

A Teoria da Sintaxe mais Simples ${ }^{9}$ é um modelo de gramática baseado em restrições que propõe uma arquitetura em paralelo, em que fonologia, sintaxe e semântica compõem, em conjunto, três níveis de estruturação linguística não-hierárquicos entre si. Cada sentença bem formada da língua é, pois, representada e licenciada em cada nível de forma concomitante e independente. Essa proposta distribui a complexidade estrutural entre três "módulos", retirando a sobrecarga da sintaxe, que não precisa mais comportar, sozinha, todos os fenômenos linguísticos essenciais.

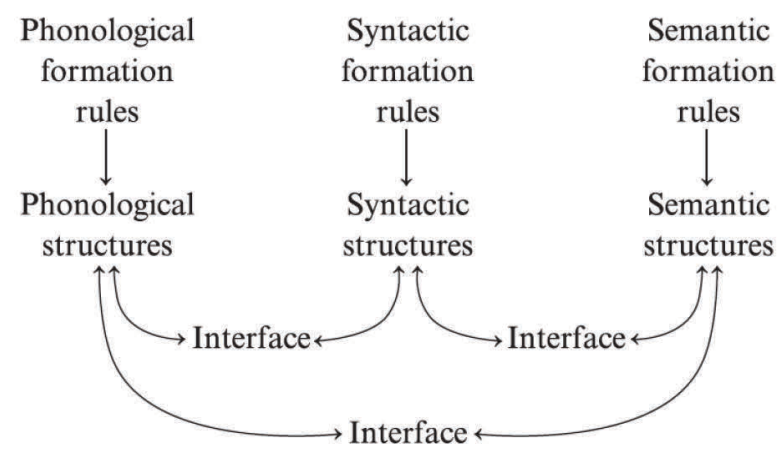

Diagrama 2: A arquitetura em paralelo (JACKENDOFF, 2007, p. 49)

Essa arquitetura é possível graças à rejeição do que Culicover e Jackendoff denominam Princípio da Uniformidade de Interface entre sintaxe e semântica (PUI):

Uniformidade de Interface

"A interface sintaxe-semântica é simples ao máximo, de modo que o significado é mapeado de modo transparente na estrutura sintática; e é uniforme ao máximo, de forma que o mesmo significado é sempre mapeado com a mesma estrutura sintática.” (CULICOVER; JACKENDOFF, 2005, p. 6)

Na SMS, não há obrigatoriedade de Uniformidade de Interface entre sintaxe e semântica, pois a sintaxe não é o eixo central de geração linguística. Essa arquitetura radicalmente modular proporciona uma maior autonomia à sintaxe, que deixa de ter que atender a condições de legibilidade tão severas na interface com a semântica (cf. CHOMSKY, 2000).

Distanciando-se da GGT, a SMS opta, como critério de parcimônia teórica, pela simplificação da estrutura, enquanto as regras de formação de constituintes (PS rules) tornam-se mais refinadas; a GGT, inversamente, reduz as regras de PS, o que conduz à projeção de estruturas mais detalhadas (MILIORINI, 2018). Entretanto, as duas abordagens se aproximam por considerarem a linguagem como um sistema gerativo, inato, mental, formalizável e modular.

Dentro desse quadro, a subpredicação aparece como um objeto de estudo interessante, pois é um fenômeno tradicionalmente analisado tomando-se o PUI como pressuposto: toda subpredicação semântica é uniformemente projetada como small clause na sintaxe. Além disso, a postulação irrestrita de SCs seguindo o PUI traz outras complicações à análise. Tomemos, por exemplo, as propostas que defendem a projeção de um núcleo funcional Agr para as SCs. Tendo em vista a concordância de gênero e número em línguas como o português (cf. (38)), a presunção de uniformidade pode levar a ramificações com categorias vazias, mesmo para estruturas sem concordância explícita, como em (39) abaixo:

${ }^{9}$ No início da proposta, Culicover (2000) chamou a teoria de Minimalismo Concreto. 


$$
\text { Paula quer [AGR [NP a filha] [AGR' [ AGR -a] [AP realizad-]] }
$$

$$
\text { Paula quer [AGR [NP O filho] [AGR' [ AGR Ø] [AP feliz]] }
$$

Como na SMS não há categorias vazias, as duas estruturas seriam projetadas de forma um pouco diferente. Em casos em que o morfema não tem expressão fonológica, não seria gerado um núcleo de concordância Agr na sintaxe.

Segundo Culicover e Jackendoff (2005), a análise de dados empíricos nos permite argumentar tanto contra, quanto a favor da projeção do sintagma SC. O fenômeno da subpredicação pode, portanto, ser representado sintaticamente de duas maneiras distintas. Como apresentaremos na análise, temos evidências para afirmar que há casos em que a subpredicação corresponde a um único constituinte sintático e há casos em que isso não ocorre. Essa análise só é possível uma vez que a abordagem aqui adotada não está comprometida com a obrigatoriedade de uniformidade - podemos, então, propor que um mesmo fenômeno semântico se manifeste sintaticamente por meio de estruturas distintas. Alguns testes de constituência serão aplicados para verificar se os verbos analisados subcategorizam ou não um sintagma do tipo SC.

\subsection{AS REGRAS DE FORMAÇÃO SINTAGMÁTICA E OS TESTES DE CONSTITUÊNCIA NA SINTAXE MAIS SIMPLES}

Haegeman (2006, p. 74) recomenda a aplicação de testes de constituência para "[...] ver se a linguagem por si só fornece alguma indicação de que uma certa sequência de palavras age ou é percebida como uma unidade [i.e. um sintagma].” Tais testes vão nos auxiliar a determinar quando uma subpredicação semântica pode corresponder a um sintagma do tipo SC. Embora a autora preconize o uso desses testes pressupondo o aparato teórico da GGT, eles também podem ser utilizados para verificar a formação ou não de sintagmas na SMS, uma vez que esta teoria também prevê constituintes sintáticos formados hierarquicamente. Vamos agora definir melhor as regras de formação de constituintes dentro desta abordagem.

Culicover e Jackendoff (2005) propõem que os princípios que caracterizam a geração dos sintagmas devam ser baseados em restrições, em vez de em regras de reescritura de caráter derivacional. As regras de estrutura sintagmática, na SMS, são divididas em dois grupos: (i) princípios de constituência e (ii) princípios de ordem linear. Segundo os autores, a vantagem dessa divisão em dois grupos de restrições relativamente autônomos é que se torna possível rearranjar constituintes sem que isso afete a hierarquia das sentenças. Essa propriedade parece particularmente útil no trato de línguas com ordem de palavras mais livre, por exemplo.

\begin{tabular}{|c|c|}
\hline Constituência & Ordem \\
\hline a. $\{\mathrm{s}(\mathrm{XP} / \mathrm{C}) \mathrm{NP} T(\mathrm{PP} / \operatorname{AdvP})(\mathrm{VP})\}$ & {$[\mathrm{XP} / \mathrm{C} ; \mathrm{NP}>$ default $\mathrm{T}>$ default $\mathrm{VP}$} \\
\hline b. $\{$ sc NP AP/PP/ing + VP $\}$ & $\mathrm{NP}>\mathrm{AP} / \mathrm{PP} /$ ing $+\mathrm{VP}$ \\
\hline
\end{tabular}
Abaixo, temos o quadro das regras de estrutura sintagmática para formação de Ss, e SCs ${ }^{10}$ :

Onde:

$[X P: X P$ está na periferia esquerda

$\mathrm{X}>\mathrm{Y}$ : X precede $\mathrm{Y}$

$\mathrm{X}>_{\text {default }} \mathrm{Y}: \mathrm{X}$ preferencialmente precede $\mathrm{Y}$ (i.e., essa é a ordem padrão)

${ }^{10}$ As regras aqui citadas são propostas para a língua inglesa. Os autores afirmam que muitas delas equivalem a especializações de princípios mais gerais fornecidos
pela GU, enquanto outras são construções particulares do inglês. Ainda não há, na literatura em SMS, regras específicas de formação de sintagmas para o português. 
A regra (a) define como são constituídos os sintagmas sentenciais (S). A primeira coluna, relativa aos princípios de constituência, mostra XP como posição de tópico que pode ser preenchida por sintagmas de diferentes categorias, podendo também alternar com o complementizador C. S tem sempre NP e T como constituintes, mas o VP é opcional, permitindo elipse do verbo. A segunda coluna determina a ordem linear: o tópico, quando presente, ocupa sempre a periferia esquerda; o NP-sujeito precede T como ordem default, da mesma maneira como T precede VP; os advérbios sentenciais são ordenados de modo livre.

A regra (b), por sua vez, caracteriza a geração de constituintes do tipo SC-complemento: o sintagma SC é sempre composto por NP + AP/PP/VP(gerúndio); NP sempre precede seu irmão. Os autores não reconhecem, ao menos em inglês, a possibilidade de NP ocorrendo como predicado. É sabido, contudo, que, ao menos em PB, essa construção existe:

(40) João quer seu candidato [NP reitor da universidade]

Os autores também não definem, na regra de linearização para SCs, a possibilidade de inversão entre sujeito e predicado, como ocorre em (41):

(41) Lucas imaginou [pred nua] [suj a sua vizinha]

Note-se que a estrutura sintática adotada pela SMS é flat: ela é formada por ramificações múltiplas (não necessariamente binárias), sem níveis de barra (X’), e apresenta uma projeção mais simples para a sentenças encaixadas, sem as categorias sentenciais endocêntricas CP e IP:

(42) João disse que Ana estuda matemática.

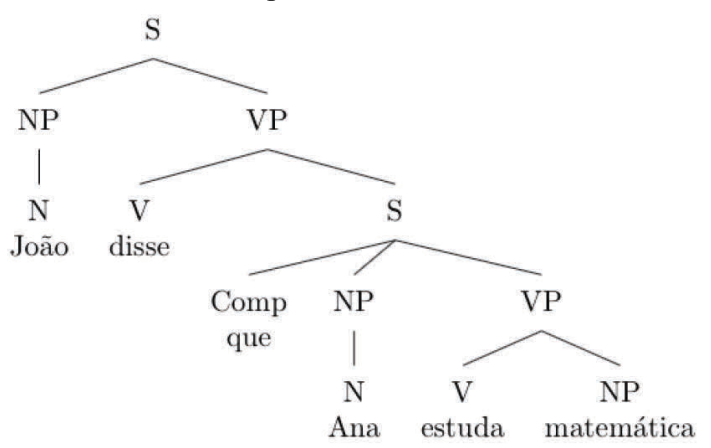

Como apresentando brevemente, portanto, a estruturação dos sintagmas na SMS é um pouco diferente da proposta da GGT, embora se assemelhe a ela em alguns aspectos. Esse excurso pela teoria sintagmática proposta na SMS é importante para evitar eventuais incompreensões na próxima seção. Não queremos que a referência informal a "movimentos" de sintagmas no contexto da aplicação dos testes de constituência implique qualquer tipo de adesão a um modelo transformacional de gramática. Para a SMS, como para outras teorias "monoestratais" (e.g. HPSG e LFG), não há operações de descolamento de constituintes, pois não são postuladas estruturas subjacentes ou etapas derivacionais. O que há, todavia, são sintagmas constituídos hierarquicamente, entendidos como unidades. Isso basta para que possamos falar, metaforicamente, de "movimento", entendendo que tal metáfora corresponde a uma relação no nível da linearidade - nível de geração das sentenças em SMS - entre sentenças geradas de modo independente. Não estamos, portanto, transformando uma estrutura primitiva por derivação, mas criando novas estruturas a partir de uma relação de semelhança com a sequência testada, em consonância com as regras sintáticas que licenciam essas formações. ${ }^{11}$

Isso é suficiente para que os testes de constituência funcionem de maneira muito parecida com o que já se faz há tempos em GGT. Quando movemos uma sequência de palavras em SMS, estamos deslocando sintagmas inteiros e criando novas sentenças, de acordo com as possibilidades facultadas pelos princípios da gramática. Se conseguimos, por exemplo, topicalizar uma sequência de palavras,

\footnotetext{
${ }^{11}$ Essa noção de transformação é mais próxima à proposta inicial de Harris (apud CHOMSKY, 1979), em que transformar uma sentença em outra não implica uma relação derivacional entre ambas.
} 
isso significa que essa sequência é um sintagma porque (i) ela pôde ser "movida" - no sentido de "movimento" que definimos acima - e (ii) ela pôde ocupar a posição de tópico na periferia esquerda da sentença, a qual só pode ser ocupada por sintagmas inteiros (XPs), como determina a regra para formação de Ss (cf. Quadro 2).

Os testes de substituição, de formação de perguntas QU e de focalização operam da mesma maneira, tomando as regras de formação de constituintes como base para a manipulação das sentenças e a criação de novas estruturas semelhantes àquelas que estão sendo testadas. O teste da substituição, por exemplo, é um recurso anafórico de retomada sintática e semântica; se uma sequência puder ser substituída por outra, significa que temos ali um sintagma. Na formação de perguntas QU, temos igualmente uma anáfora (ou catáfora), que ocupa a posição de início da sentença. Uma estrutura de foco (como as clivadas e pseudo-clivadas) também precisa ser preenchida por um sintagma. Note-se que estes últimos casos também não são analisados como transformações gramaticais indecomponíveis na GGT há muito tempo.

\section{ANÁLISE DE DADOS}

Analisaremos sentenças com verbos que, em PB, podem selecionar semanticamente uma subpredicação (cf. seção 2): querer, ver, encontrar, eleger, proclamar, ouvir, nomear, declarar, esperar, sentir, pensar, imaginar, julgar, considerar e visualizar ${ }^{12}$. Tais sentenças serão elaboradas por nós e o método de análise utilizado será o introspectivo, em que os próprios autores julgam a aceitabilidade das sentenças analisadas enquanto falantes nativos de PB. As sentenças serão submetidas a testes de constituência para verificar em quais casos a subpredicação corresponde a um único constituinte sintático; ou seja, buscamos determinar quais verbos do PB selecionam uma SC sintática relacionada à subpredicação semântica.

Culicover e Jackendoff (2005) sugerem que apenas algumas estruturas tipicamente analisadas como SCs pela GGT de fato têm sua natureza sintagmática empiricamente justificada. Dado que as SCs são consideradas constituintes completos, é esperado que elas exibam um conjunto de propriedades especiais que são associadas a constituintes tanto em teorias como a GGT e quanto na SMS (pois ambas compartilham a ideia de sintaxe como uma representação hierárquica). São essas as propriedades isoladas em testes de constituência, como aqueles propostos por Haegeman (2006).

Quatro testes são aplicados por Culicover e Jackendoff (2005) para a verificação da formação ou não de um sintagma do tipo SC: (i) focalização por pseudo-clivadas, (ii) inserção de advérbios, (iii) substituição do predicado por uma forma gerundiva e (iv) sentenças resultativas do tipo tão/tanto(a)(s) ... que (that-resultatives). A maior parte desses testes serve não apenas para diagnosticar a formação ou não de um constituinte (como os testes de Haegeman (2006)), mas também para identificar quando o constituinte selecionado pelo verbo tem natureza sentencial. Utilizaremos em nossa análise apenas o primeiro deles, a focalização por pseudoclivadas, pois os demais parecem não funcionar tão bem para o português. ${ }^{13}$

\footnotetext{
${ }^{12}$ Alguns desses verbos são tratados pela GGT como selecionadores de SC complemento, como julgar, e outros, como encontrar, por exemplo, são associados à ocorrência de SC adjunto:

(a) Ana julga [scsua irmã irresponsável]

(b) Ana encontrou sua irmãi $[$ sc PROi desesperada $]$

Gomes e Foltran (2009) classificam esses dois grupos em (i) predicação primária: SCs selecionadas como complemento dos verbos (cf. (a)) e (ii) predicação secundária: SCs na posição de adjuntos dos verbos (cf. (b)). A divisão proposta pelas autoras segue, todavia, um critério sintático, baseado em testes formulados por Rothstein $(1995 ; 2001)$ para diferenciação entre predicados primários e secundários. Como partimos aqui de um objeto delimitado semanticamente (a subpredicação), essa diferença não será relevante para nós. Além disso, a SMS não diferencia adjuntos de complementos no componente sintagmático, formalizando a distinção no subnível sintático da Camada de Funções Gramaticais (Grammatical Function Tier (GFT)) e na estrutura semântica (cf. CULICOVER; JACKENDOFF, 2005, cap. 6; JACKENDOFF, 2002).
}

Além disso, não serão tampouco analisados verbos como permanecer, estar, parecer, ficar etc. Por serem inacusativos (PERLMUTTER, 1978; BURZIO, 1986), esses verbos comportam-se de maneira distinta dos demais e demandariam tratamento específico, que não cabe no escopo pretendido por este artigo. Nosso objetivo não é, portanto, analisar todos os tipos de subpredicação ou de SC na língua.

${ }^{13}$ Para uma discussão dos demais testes utilizados por Culicover e Jackendoff (2005) para verificar a formação de estruturas do tipo SC, cf. Miliorini (2016). 
É importante salientar que a utilização de um número pequeno de testes não é garantia suficiente para comprovar a natureza de uma sequência examinada. Mesmo que os testes isolem algumas propriedades gramaticais das construções envolvidas, o resultado de cada aplicação pode ser afetado por nossas intuições de aceitabilidade, que nem sempre correspondem univocamente à gramaticalidade de uma sentença. Como Chomsky (1965) argumentou, a aceitabilidade intuitiva de uma construção pode estar sujeita à influência de uma série de fatores extragramaticais como frequência, lapsos de atenção, cansaço etc. Ademais, uma vez que as propriedades de cada construção sintática são sempre resultantes de vários princípios e regras gramaticais independentes (cf. CARNIE, 2007), a aplicação de um único teste pode levar a um falso resultado, especialmente quando as intuições a seu respeito são instáveis. Por isso, a fim de assegurar maior credibilidade às nossas conclusões, é ideal que um bom número de testes fundamentados por intuições robustas seja aplicado a cada sequência analisada.

Aplicaremos, aqui, portanto, cinco testes tradicionais: (i) substituição por pronome (também chamada de pronominalização), (ii) topicalização, (iii) formação de perguntas QU, (iv) focalização por clivada e (v) focalização por pseudo-clivada. Dentre os testes citados, como dissemos acima, Culicover e Jackendoff (2005) utilizam apenas o teste das pseudo-clivadas como forma de investigar a natureza categorial das sequências sob exame. Para diversificar e enriquecer a análise, adotamos os demais testes gerais de constituência compilados por Haegeman (2006).

Depois de analisados, os verbos foram classificados em duas categorias: (i) aqueles que licenciam uma subpredicação através de um constituinte do tipo SC e (ii) aqueles que não expressam a subpredicação através de SC. A análise correspondente aos do primeiro grupo está na seção 5.1 e aos do segundo grupo, na seção 5.2. Os verbos foram categorizados posteriormente à análise e a partir dela, mas, para fins expositivos, são apresentados aqui reorganizados em duas seções distintas.

\subsection{VERBOS QUE LICENCIAM SC}

Nesta primeira seção, analisamos os verbos visualizar, ver, ouvir, sentir, imaginar, querer, esperar, pensar e encontrar. Iniciemos com os verbos visualizar, ver, ouvir e sentir.

(43) a. Eu visualizei a tese concluída.

b. PRONOMINALIZAÇÃO: Eu visualizei isso.

c. TOPICALIZAÇÃO: A tese concluída, eu visualizei.

d. PERGUNTA QU: Eu visualizei o quê? A tese concluída.

e. PSEUDO-CLIVADA: O que eu visualizei foi a tese concluída.

f. CLIVADA: Foi a tese concluída que eu visualizei.

g. [vp visualizar [sc NP AP]]

(44) a. Bruno viu o tio dormindo.

b. PRONOMINALIZAÇÃO: Bruno viu isso.

c. TOPICALIZAÇÃO: O tio dormindo, Bruno viu.

d. PERGUNTA QU: Bruno viu o quê? O tio dormindo.

e. PSEUDO-CLIVADA: O que Bruno viu foi o tio dormindo.

f. CLIVADA: Foi o tio dormindo que Bruno viu.

g. [vp ver [sc NP VP]]

(45) a. Nós ouvimos a Elis cantando.

b. PRONOMINALIZAÇÃO: Nós ouvimos isso.

c. TOPICALIZAÇÃO: A Elis cantando, nós ouvimos.

d. PERGUNTA QU: Nós ouvimos o quê? A Elis cantando.

e. PSEUDO-CLIVADA: O que nós ouvimos foi a Elis cantando.

f. CLIVADA: Foi a Elis cantando que nós ouvimos. 
g. [vp ouvir [sc NP VP]]

(46) a. Ele sentiu o mundo desabando sob seus pés.

b. PRONOMINALIZAÇÃO: Ele sentiu isso.

c. TOPICALIZAÇÃO: O mundo desabando sob seus pés, ele sentiu.

d. PERGUNTA QU: Ele sentiu o quê? O mundo desabando sob seus pés.

e. PSEUDO-CLIVADA: O que ele sentiu foi o mundo desabando sob seus pés.

f. CLIVADA: Foi o mundo desabando sob seus pés que ele sentiu.

g. [vp sentir [sc NP VP]]

O sentido da sentença em (43a) parece manter-se preservado quando aplicam-se os testes da pronominalização em (43b), da topicalização em (43c), da pergunta-QU em (43d), da pseudo-clivada em (43e) e da clivada em (43f), mostrando que o complemento do verbo visualizar seleciona um constituinte de natureza predicativa com as caraterísticas sintáticas que Stowell (1983) atribui às SCs. A estrutura sintática que se apresenta é, portanto, a expressa em (43g), em que há um sintagma do tipo SC em um nó independente, projetado a partir de [NP a tese] e [AP concluída], ocupando a posição de complemento do verbo.

Em (44b,c,d,e,f), aplicamos os mesmos testes aos complementos de ver e o sentido em (44a) também parece se conservar. As sentenças (45) e (46) também passam em todos os testes, pois preservam seu sentido original quando submetidas a cada um deles.

Concluímos, portanto, que verbos como visualizar, ver, ouvir e sentir podem selecionar como complemento constituintes sintáticos do tipo SC. Esses verbos apresentam em comum a propriedade de serem verbos que denotam estados perceptuais ${ }^{14}$. Não é, todavia, o caso que apenas verbos de percepção selecionem sintaticamente um constituinte SC como complemento.

Vejamos agora os testes aplicados aos verbos imaginar, querer, esperar, pensar e encontrar:

(47) a. Eu imaginei minha vida ao seu lado.

b. PRONOMINALIZAÇÃO: Eu imaginei isso.

c. TOPICALIZAÇÃO: A minha vida ao seu lado, eu imaginei.

d. PERGUNTA QU: Eu imaginei o quê?? Minha vida ao seu lado.

e. PSEUDO-CLIVADA: O que eu imaginei foi minha vida ao seu lado.

f. CLIVADA: Foi a minha vida ao seu lado que eu imaginei.

g. [vp imaginar [sc NP PP]]

(48) a. Júlia quer a amiga feliz.

b. PRONOMINALIZAÇÃO: Júlia quer isso.

c. TOPICALIZAÇÃO: A amiga feliz, Júlia quer.

d. PERGUNTA QU: Júlia quer o quê? A amiga feliz.

e. PSEUDO-CLIVADA: O que Júlia quer é a amiga feliz.

f. CLIVADA: É a amiga feliz que Júlia quer.

g. [vp querer [sc NP AP]]

(49) a. A torcida espera o Flamengo na Libertadores.

\footnotetext{
${ }^{14}$ Os verbos de percepção aqui analisados selecionam uma subpredicação semântica e uma small clause sintática tanto na interpretação comum quanto em uma interpretação imaginativa (na qual o falante não se compromete com a verdade da predicação expressa no complemento). Por exemplo:

i.Maria viu João correndo. (percepção)

CLIVADA: Foi João correndo que Maria viu.

ii.Maria viu João caindo aos seus pés. (percepção imaginativa)

CLIVADA: Foi João caindo aos seus pés que Maria viu.
} 
b. PRONOMINALIZAÇÃO: A torcida espera isso.

c. TOPICALIZAÇÃO: O Flamengo na Libertadores, a torcida espera.

d. PERGUNTA QU: A torcida espera o quê? O Flamengo na Libertadores.

e. PSEUDO-CLIVADA: O que a torcida espera é o Flamengo na Libertadores.

f. CLIVADA: É o Flamengo na Libertadores que a torcida espera.

g. [vp esperar [sc NP PP]]

(50) a. Ana pensou no Thiago de sunga verde.

b. PRONOMINALIZAÇÃO: Ana pensou nisso.

c. TOPICALIZAÇÃO: No Thiago de sunga verde, Ana pensou.

d. PERGUNTA QU: Ana pensou em quê? No Thiago de sunga verde.

e. PSEUDO-CLIVADA: ? O que Ana pensou foi no Thiago de sunga verde.

f. CLIVADA: Foi no Thiago de sunga verde que Ana pensou.

g. [vp pensar [sc NP PP]]

(51) a. Maria encontrou Fábio preocupado.

b. PRONOMINALIZAÇÃO: ? Maria encontrou isso.

c. TOPICALIZAÇÃO: Fábio preocupado, Maria encontrou.

d. PERGUNTA QU: Maria encontrou o quê? Fábio preocupado.

e. PSEUDO-CLIVADA: O que Maria encontrou foi Fábio preocupado.

f. CLIVADA: Foi Fábio preocupado que Maria encontrou.

g. [vp encontrar [sc NP AP]]

Obtivemos um resultado positivo com a aplicação dos testes às sentenças (47), (48), (49), (50) e (51), o que indica, novamente, a formação de um sintagma do tipo SC nas subpredicações selecionadas pelos verbos imaginar, querer, pensar e encontrar ${ }^{15}$. Entretanto, a sentença resultante do teste da focalização em (50e) pode parecer um pouco estranha, devido à impossibilidade de manter a regência oblíqua do verbo na formação da pseudo-clivada. O teste da substituição em (51b) também parece não funcionar muito bem, pois o pronome isso não dá conta de retomar o sentido de [Fábio preocupado]. ${ }^{16}$ Como frisamos no início da análise, a aplicação de apenas um teste para diagnosticar constituintes não é suficiente, pois nem todas as sentenças comportam-se do mesmo modo ao serem manipuladas. É por isso que estamos utilizando um número maior de testes para inferir a natureza de cada exemplo. Os resultados adversos em (50e) e em (51b) não configuram, pois, um problema para a nossa conclusão.

A partir da análise das sentenças (43), (44), (45) e (46), levantamos a hipótese de que é uma característica de verbos de percepção selecionar um constituinte sintático do tipo SC quando há uma subpredicação. Ao aplicarmos os testes a outros verbos de percepção, como notar, perceber, observar, escutar etc., verificamos que, de fato, esse parece ser um comportamento homogêneo, i. e., verbos de percepção que selecionam semanticamente uma subpredicação irão selecionar sintaticamente um constituinte do tipo SC. ${ }^{17}$ Contudo, não é apenas essa classe de verbos que subcategoriza SCs, como vimos nos exemplos (47), (48), (49), (50) e (51) acima: os verbos imaginar, querer, esperar, pensar e encontrar também o fazem. Isso mostra que verbos de outros campos semânticos se comportam sintaticamente da mesma forma que os verbos de percepção quando selecionam semanticamente uma subpredicação. Nossa análise atestou, portanto, que os verbos ver, ouvir, imaginar, querer, sentir, pensar, visualizar, ouvir, esperar e encontrar

\footnotetext{
${ }^{15}$ Gomes e Foltran (2009) aplicam testes sugeridos por Rothstein $(1995 ; 2001)$ para diferenciar SCs complemento de SCs adjunto. Segundo as autoras, quando os testes apontam para a não-formação de um constituinte, teríamos uma SC adjunto, pois seu sujeito seria ocupado por uma categoria vazia PRO e, por isso, não formaria um sintagma com o predicado. Um dos verbos apresentados pelas autoras como exemplo de construção com SC adjunto é justamente encontrar. Em nossa análise, todavia, a partir de testes diferentes (os testes reunidos por Haegeman (2006)), obtivemos um resultado distinto: encontrar seleciona como complemento um constituinte único de tipo SC. Como os testes que empregamos aqui são também muito adotados na GGT, nosso resultado apresenta um desafio à metodologia utilizada por Gomes e Foltran (2009) para diferenciar SCs complemento de SCs adjuntos.

${ }^{16}$ Adotamos a convenção de colocar "?” no início de uma sentença para indicar que a sentença resultante após o teste não preserva o sentido da sentença original mesmo que seja uma construção gramatical possível na língua.

${ }^{17}$ Nosso objeto, aqui, não são os verbos de percepção; portanto, uma análise mais cuidadosa e exaustiva teria de ser feita para averiguar se essa generalização é, de fato, plenamente válida.
} 
selecionam um sintagma do tipo SC associado à subpredicação. Para esses verbos teremos então uma estrutura sintática muito semelhante àquela que é proposta para as subpredicações em GGT.

Mioto, Figueiredo Silva e Lopes $(2007,2013)$ aplicam o mesmo teste das clivadas que adotamos aqui, mas com um objetivo distinto: o de desfazer a ambiguidade estrutural de sentenças como as que analisamos, cujos verbos podem selecionar como complemento sintagmas de natureza sentencial (SCs) ou de natureza não-sentencial (NPs). Os autores mostram que, se o sintagma for um NP, ele não pode ser separado na focalização, uma vez que apenas sintagmas inteiros podem ser focalizados, e não fragmentos de sintagmas. Assim, a sentença (52) apresenta duas leituras, que poderiam ser desambiguizadas nas focalizações em (53) e (54):

(52) Ana viu o vizinho alegre.

(53) Foi o vizinho alegre que Ana viu.

(54) Foi o vizinho que Ana viu alegre.

A intenção do teste é mostrar que em (53) [o vizinho alegre] é um único sintagma NP, pois esse é o constituinte focalizado na clivada. Entretanto, nossos testes aplicados às sentenças (43) a (51) acima evidenciaram que não são apenas os sintagmas nominais (NPs) que podem ser clivados. É possível, portanto, que (53) seja ainda estruturalmente ambígua entre um NP e uma SC. Retomaremos essa questão ao fim da próxima seção.

Nosso objeto de análise foi delimitado semanticamente na seção 2, em que buscamos mostrar, através da aplicação de testes de paráfrase por sentença encaixada, a natureza semântica do fenômeno como uma (sub)predicação, em oposição a verbos triargumentais. Os testes de Haegeman (2006), aplicados às sentenças (43) a (51) permitem inferir a constituência das sequências analisadas.

O teste de Mioto, Figueiredo Silva e Lopes (2007; 2013) é interessante pois fornece evidência de que os constituintes subcategorizados pelos verbos aqui analisados não são NPs, mas sintagmas mais complexos. Como todos os sintagmas subcategorizados pelos verbos tratados nesta seção são capazes de ser cindidos em construções como (54), eles não têm como ser NPs. Entretanto, as evidências que mencionamos deixam a natureza exata desses sintagmas ainda em aberto. Tais constituintes poderiam ter natureza de AgrPs, como proposto por Haegeman (1994) e por Cardinaletti e Guasti (1995), por exemplo, ou de SCs, como proposto por Stowell $(1983 ; 1995)$ e por Chomsky (1995). Adotamos aqui esta última proposta devido ao nosso compromisso com o modelo específico proposto pela SMS de Culicover e Jackendoff (2005), que não prevê a projeção de categorias funcionais como AgrPs. Admitimos, todavia, que nossos resultados obtidos a partir da aplicação dos testes são compatíveis com ambas as representações.

\subsection{VERBOS QUE NÃO LICENCIAM SC}

Vejamos, agora, como fica a análise para os verbos que selecionam semanticamente uma subpredicação, mas que, segundo nossos resultados, não subcategorizam uma SC sintática: eleger, proclamar, nomear, declarar, considerar e julgar.

(55) a. Os alunos elegeram a Ana coordenadora do curso.

b. PRONOMINALIZAÇÃO: ? Os alunos elegeram isso.

c. TOPICALIZAÇÃO: ? A Ana coordenadora do curso, os alunos elegeram.

d. PERGUNTA QU: ? Os alunos elegeram o quê? A Ana coordenadora do curso.

e. PSEUDO-CLIVADA: ? O que os alunos elegeram foi a Ana coordenadora do curso.

f. CLIVADA: ? Foi a Ana coordenadora do curso que os alunos elegeram.

g. [vp eleger NP NP]

(56) a. D. Pedro proclamou o Brasil independente.

b. PRONOMINALIZAÇÃO: ? D. Pedro proclamou isso.

c. TOPICALIZAÇÃO: ? O Brasil independente, D. Pedro proclamou. 
d. PERGUNTA QU: ? D. Pedro proclamou o quê? O Brasil independente.

e. PSEUDO-CLIVADA: ? O que D. Pedro proclamou foi o Brasil independente.

f. CLIVADA: ? Foi o Brasil independente que D. Pedro proclamou.

g. [vp proclamar NP AP]

a. Temer nomeou Meirelles ministro da Fazenda.

b. PRONOMINALIZAÇÃO: ? Temer nomeou isso.

c. TOPICALIZAÇÃO: ? Meirelles ministro da Fazenda, Temer nomeou.

d. PERGUNTA QU: ? Temer nomeou o quê? Meirelles ministro da Fazenda.

e. PSEUDO-CLIVADA: ? O que Temer nomeou foi Meirelles ministro da Fazenda.

f. CLIVADA: ? Foi Meirelles ministro da Fazenda que Temer nomeou.

g. [vP nomear NP NP]

(58) a. A reitora declarou aberta a sessão.

b. PRONOMINALIZAÇÃO: ? A reitora declarou isso. (não predicativo)

c. TOPICALIZAÇÃO: ? Aberta a sessão, a reitora declarou.

d. PERGUNTA QU: ? A reitora declarou o quê? Aberta a sessão.

e. PSEUDO-CLIVADA: ? O que a reitora declarou foi aberta a sessão.

f. CLIVADA: ? Foi aberta a sessão que a reitora declarou.

g. [vP declarar AP NP]

Os mesmos testes aplicados aos verbos eleger, proclamar, nomear e declarar apontam para um resultado oposto ao da seção anterior: as sequências testadas não retêm seus sentidos após serem manipuladas - evidência de que esses verbos não selecionam como complemento constituintes do tipo SC. Em (55c), a sentença resultante soa aceitável, mas apenas sob outra interpretação: Os alunos elegeram (como Paraninfa) a Ana que é coordenadora do curso (não a Ana que é professora de sintaxe). Nesse caso, a leitura não é predicativa, pois o termo Ana não está sendo usado, mas apenas mencionado (cf. SEARLE, 1969; MORTARI, 2001). O que temos aqui é uma descrição definida metalinguística, e não uma predicação. O mesmo acontece em (55f).

O teste da pronominalização em (56b) parece recuperar um outro sentido do verbo proclamar, que não seleciona uma subpredicação: o pronome isso poderia estar retomando um argumento nominal ou sentencial, como em D. Pedro proclamou [NP $a$ independência do Brasil / s que o Brasilé independente]; mas não exatamente um constituinte que expressa uma subpredicação. Logo, nessa leitura o pronome não retomaria uma SC. O mesmo teste apresenta resultados semelhantes para (58b). Outras sentenças em (56) soam aceitáveis se interpretarmos Brasil independente como uma descrição definida, mas não como uma predicação.

Já (57f), uma sentença clivada, pode funcionar se entendemos o predicado ministro da Fazenda como um aposto, como em Foi Meirelles, ministro da fazenda, que Temer nomeou (como seu assessor em assuntos econômicos). Novamente, como o sentido da sentença original não é preservado na clivada, inferimos que o verbo nomear também não pode subcategorizar um constituinte do tipo SC.

Todos os demais testes aplicados às sentenças (55), (56), (57) e (58) apontam nitidamente para a não-formação de um sintagma do tipo SC como complemento. Por essa razão, tendo em vista que não há motivação empírica para a projeção de um sintagma separado do tipo SC, a projeção sintática dos complementos desses verbos é a que propomos em (55g, 56g, 57g, 58g), em que os constituintes sintáticos relativos ao sujeito e ao predicado da subpredicação são ramificações diretas de VP, como em estruturas triargumentais.

Vejamos agora os verbos considerar e julgar:

b. PRONOMINALIZAÇÃO: ? A igreja considera isso. 
c. TOPICALIZAÇÃO: ? O abordo imoral, a igreja considera.

d. PERGUNTA QU: ? A igreja considera o quê? O aborto imoral.

e. PSEUDO-CLIVADA: ? O que a igreja considera é o aborto imoral.

f. CLIVADA: ? É o aborto imoral que a igreja considera. ${ }^{18}$

g. [vP considerar NP AP]

(60) a. O juiz julgou improcedente minha ação.

b. PRONOMINALIZAÇÃO: ? O juiz julgou isso.

c. TOPICALIZAÇÃO: ? Improcedente minha ação, o juiz julgou.

d. PERGUNTA QU: ? O juiz julgou o que? Improcedente minha ação.

e. PSEUDO-CLIVADA: ? O que o juiz julgou foi improcedente minha ação.

f. CLIVADA: ? Foi improcedente minha ação que o juiz julgou.

g. [vP julgar AP NP]

As sentenças em (59a) e (60a) também não mantêm sua interpretação quando submetidas aos cinco testes. No último caso, com o verbo julgar, quando aplicamos o teste de pronominalização, por exemplo, temos uma sentença possível, mas que traduz outro significado: o pronome isso parece retomar apenas o sujeito da subpredicação como em o juiz julgou a minha ação. As demais sentenças em (59) e (60) são claramente anômalas, mostrando que os verbos considerar e julgar não selecionam como complemento um constituinte.

Recuperemos aqui a discussão de Mioto, Figueiredo Silva e Lopes (2007; 2013), referida na seção anterior. Os autores aplicam alguns dos mesmos testes de constituência que aplicamos aqui com uma finalidade distinta: desfazer a ambiguidade estrutural em sentenças que apresentam a leitura predicativa como uma de suas acepções. Vejamos um exemplo, citado pelos autores: O juiz julgou a ré culpada.

Aplicando o teste da clivagem, por exemplo, obtemos as seguintes opções:

(62) a. Foi [aquela ré culpada] que o juiz julgou.

(63) a. Foi [aquela ré] que o juiz julgou [culpada].

Em (62), a unidade [NP aquela ré culpada] mantém-se "ensanduichada" entre a cópula e o elemento QU, o que, para os autores, é indício de que o adjetivo culpada integra um sintagma nominal NP com função puramente referencial (ao menos nessa sentença). Isto é, o adjetivo culpada cumpre uma função de identificação, e não de predicação (para retomar os termos de Searle (1969)). Entretanto, quando separamos [Np aquela ré] de [AP culpada] em (63a), obtemos a leitura predicativa, ou seja, culpada passa a designar o veredito do juiz aplicado à ré.

Os autores utilizam esse e outros testes para argumentar a favor da formação de small clauses nesta última leitura. Entretanto, embora os testes de fato sirvam para a desambiguação das leituras referenciais e predicativas do complemento, o que eles indicam é apenas a formação de dois sintagmas distintos ([NP aquela ré] e [AP culpada]) no segundo caso. A análise de Mioto, Figueiredo Silva e Lopes (2007; 2013) não diagnostica literalmente a existência de SCs, mas apenas a formação de sintagmas distintos, embora sua conclusão esteja ajustada à teoria na qual se ancoram, que prevê a obrigatoriedade ramificação binária para as projeções arbóreas.

É possível, todavia, aplicar o mesmo teste, obtendo os mesmos resultados, e argumentar em prol de uma representação distinta para a leitura predicativa explicitada por clivadas como (63a). Podemos afirmar que as unidades NP e AP realizam a predicação ligandose diretamente ao verbo, ou seja, são ramificações de VP. É claro que, para isso, temos que assumir uma concepção de estrutura

${ }^{18}$ Consideremos, aqui, a leitura predicativa de considerar, no sentido de "julgar, acreditar", não de "pensar sobre”. 
sintagmática alternativa à da GGT, na qual as ramificações podem ser n-árias e a estrutura pode ser flat. Esse é precisamente o caso da SMS.

Entretanto, a adoção de estruturas de representação n-árias (em que sujeito e predicado da subpredicação ligam-se diretamente ao verbo) não é tampouco demandada por nossos resultados. Seria possível aventar - respeitando uma versão rígida da teoria X-barra e o princípio da binaridade - que os sintagmas correspondentes ao sujeito e ao predicado da subpredicação se ramificam a partir da duplicação do nível intermediário V’, da mesma forma como os argumentos internos dos verbos triargumentais em algumas representações ${ }^{19}$. Entretanto, segundo os postulados da GGT, essa projeção também não seria muito recomendada, já que representaria de maneira sintaticamente idêntica relações semânticas bastante distintas, a saber: a relação entre um argumento e seu predicado (subpredicação sem SC) e a relação entre dois argumentos de um mesmo predicado em verbos triargumentais.

A SMS, entretanto, não assume como obrigatório o princípio da uniformidade de interface e opta pela estrutura flat como forma de representação sintática mais simples. Por isso, nessa teoria, é possível projetar as estruturas de subpredicação que não formam SCs da mesma forma como se projetam os verbos triargumentais.

(64) Ana deu o livro para João.

A sentença (64) tem um verbo triargumental, que recebe a seguinte representação em SMS:

(64')

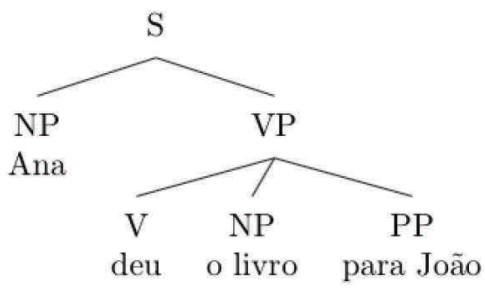

Uma subpredicação sem SC como a sentença (63), seria, portanto, estruturada da seguinte maneira, como apresentado nas análises de (55) a (60):

(63) b. O juiz julgou [a ré] [culpada].

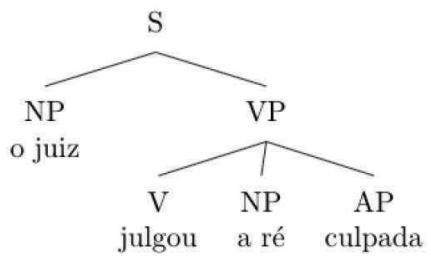

\footnotetext{
${ }^{19}$ Note-se que os verbos triargumentais, que expressam semanticamente predicados trivalentes, também não passam nos testes de constituência que aplicamos aos casos de subpredicação (cf. (64)). Tais resultados revelam uma afinidade sintática entre verbos triargumentais clássicos e os verbos que analisamos nesta seção.

(64) Ana deu o livro para João.

PRONOMINALIZACÃO: ? Ana deu isso.

TOPICALIZAÇÃO: ? O livro para João, Ana deu.

PERGUNTA QU: ? Ana deu o que? O livro para João.

PSEUDO-CLIVADA: ? O que Ana deu foi o livro para João.

CLIVADA: ? Foi o livro para João que Ana deu.
} 
Veja que aqui temos a leitura predicativa da sentença, porque podemos separar os sintagmas [a ré] e [culpada] e o adjetivo é a propriedade que o juiz atribui à ré, i. e., o veredito. A desambiguação estrutural proporcionada pelo teste de Mioto, Figueiredo Silva e Lopes (2007; 2013) continua sendo capturada pela estrutura flat, como fica claro em (62b) abaixo, que mostra o adjetivo culpada como interno ao NP:

b. O juiz julgou [a ré culpada].

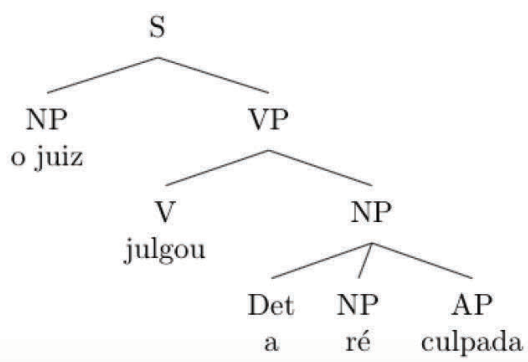

É também curioso notar que esse teste de desambiguação funciona bem apenas para sentenças cujos verbos não subcategorizam verdadeiramente uma SC. Se temos uma sentença com um complemento estruturalmente ambíguo que apresenta as possibilidades de (i) leitura referencial (descrição definida) ou (ii) leitura predicativa (subpredicação), podemos aplicar o teste da clivada para desfazer sua ambiguidade. Ao clivarmos [a ré culpada] em (62a), por exemplo, vemos que a estrutura resultante recebe apenas uma leitura referencial, de descrição definida. Como a posição de foco só pode ser ocupada por um constituinte unificado, inferimos que [a ré culpada] é, aí, um NP. Já quando separamos a sequência, como em (63a), temos indício de que [a ré] e [culpada] são dois sintagmas distintos e que, portanto, não são concatenadas a um NP (pois um NP, sendo um sintagma, não poderia ser "desmembrado" dessa maneira). Assim, o teste funciona bem para verbos como julgar e os demais analisados nesta seção, os quais não subcategorizam uma SC.

Todavia, se tentarmos aplicar o mesmo teste aos verbos que, de acordo com a nossa análise, de fato selecionam SCs, ele não dá conta de desambiguar a sentença quando clivamos a sequência de palavras inteira, como em (66):

(65) Maria viu a menina bonita.

(66) Foi [a menina bonita] que Maria viu.

(67) Foi [a menina] que Maria viu [bonita].

Em (67), a única leitura possível é a predicativa, pois separamos os constituintes, o que não seria possível caso a sequência fosse um NP. Quando clivamos [a menina bonita], entretanto, a sentença continua ambígua, tendo em vista que, como mostramos em nossos testes, as SCs, devido à sua natureza sintagmática, podem ser focalizadas. O constituinte clivado em (66), portanto, poderia ser tanto um NP quanto uma SC. O teste da clivagem consegue mostrar que a leitura de subpredicação é a única possível quando separamos o constituinte (pois, nesses casos, não é possível haver um NP), mas não desfaz a ambiguidade, para esse grupo de verbos, quando a sequência de palavras permanece unida na posição de foco.

\subsection{DISCUSSÃO DA ANÁLISE}

A partir da análise aqui desenvolvida, foi possível constatar que, dentre os verbos que podem selecionar uma subpredicação semântica, há (i) aqueles que projetam sintaticamente essa subpredicação como um sintagma do tipo SC e (ii) aqueles que projetam essa subpredicação a partir de ramificações diretas de VP, sem formar um sintagma independente. Os verbos foram então devidamente classificados em dois grupos: 


\begin{tabular}{|c|c|c|}
\hline & $\begin{array}{c}\text { Grupo 1 } \\
\text { verbos que expressam a subpredicação com } \\
\text { um sintagma do tipo SC }\end{array}$ & $\begin{array}{c}\text { Grupo 2 } \\
\text { verbos que não expressam a subpredicação } \\
\text { com um sintagma do tipo SC }\end{array}$ \\
\hline Verbos & $\begin{array}{c}\text { Visualizar } \\
\text { Ver } \\
\text { Ouvir } \\
\text { Sentir } \\
\text { Imaginar } \\
\text { Querer } \\
\text { Esperar } \\
\text { Pensar } \\
\text { Encontrar }\end{array}$ & $\begin{array}{c}\text { Eleger } \\
\text { Proclamar } \\
\text { Nomear } \\
\text { Declarar } \\
\text { Considerar } \\
\text { Julgar }\end{array}$ \\
\hline $\begin{array}{c}\text { Representação } \\
\text { sintática }\end{array}$ & & $\overbrace{\mathrm{VP}}^{\mathrm{SP}}$ \\
\hline
\end{tabular}

Os verbos do grupo 1 selecionam SCs como complemento e sua representação sintática se dá de forma semelhante ao que é tradicionalmente proposto na GGT. Já os verbos do grupo 2, ainda que expressem uma relação de subpredicação no nível semântico, não projetam um sintagma independente do tipo SC; a relação entre sujeito e predicado se dá diretamente com o verbo, em uma ramificação não-binária.

Uma característica comum à maioria dos verbos deste último grupo é seu caráter performativo. Isso sinaliza uma certa regularidade localizada entre os níveis semântico e sintático: os verbos performativos com estrutura de subpredicação não selecionam SCs, enquanto os não-performativos o fazem. Entretanto, mesmo que seja restaurado, aqui, algum grau de uniformidade, a tese da SMS de que não há uniformidade absoluta na língua permanece válida. Continua sendo o caso que há um mesmo fenômeno semântico (a subpredicação) sendo representado sintaticamente de formas distintas: sentenças completas, SCs e estruturas triargumentais (as chamadas falsas SCs). Além disso, o verbo considerar também faz parte do Grupo 2, mas não é performativo; essa regularidade apresenta, pois, exceções.

Empregamos, em nossa análise, cinco testes de constituência reunidos por Haegeman (2006). Outro teste de constituência formulado na literatura, mas não utilizado neste trabalho, é o da coordenação. De acordo com Radford (1988) e Lasnik, Depiante e Stepanov, (2000), só poderíamos coordenar sequências de palavras se elas fossem sintagmas e de mesma natureza; não seria possível, portanto, unir por meio da conjunção fragmentos sintagmáticos ou dois sintagmas de categoria distinta (NP e AP ou NP e S, por exemplo).

(68) Sarah e Helena almoçaram mais cedo.

(69) * Sarah e muito faminta almoçaram mais cedo.

A sentença (69) é agramatical porque não é possível coordenar dois sintagmas de natureza distinta - no caso, um NP e um AP. Entretanto, Culicover e Jackendoff (2005, p. 236) argumentam contra esse princípio a partir do exemplo abaixo: 


$$
\text { Cinquenta anos de gramática gerativa e o que nós aprendemos? }
$$

Nesse caso, a conjunção ocorre entre NP e S. Seria possível restaurar a validade do teste de coordenação se assumíssemos, em um nível subjacente, a representação de sentença completa contendo [cinquenta anos de gramática gerativa] como complemento de um verbo elidido. Todavia, isso é problemático pois não parece haver um critério para definir qual verbo é projetado (e posteriormente elidido) nesses casos. A estrutura subjacente seria: Passaram-se cinquenta anos? São cinquenta anos? Faz cinquenta anos? Tal questão parece ser indecidível.

Não nos interessa, aqui, entrar nas minúcias dessa discussão sobre a sintaxe das estruturas coordenadas. O que é relevante para nós é a legitimidade do uso da coordenação como teste de constituência, i. e., para diagnosticar a existência de um sintagma (qualquer que seja sua natureza categorial). Se o teste da coordenação for legítimo, poderíamos aplicá-lo às estruturas que expressam subpredicação para verificar sua categoria sintática:

(71) Júlia viu Lucas caindo e Maria rindo.

Como (71) é bem formada, o teste prevê a existência de dois sintagmas predicativos na posição de complemento de ver: [Lucas caindo] e [Maria rindo]. Esse resultado corrobora nossas conclusões, pois seria mais um meio para diagnosticar a formação de um sintagma do tipo SC sendo subcategorizado pelo verbo ver (cf. Quadro 3). A aplicação do teste a um verbo como considerar fornece, contudo, o mesmo diagnóstico, em contradição com nossa análise: José considera Luísa bela e Ana sublime.

Esse poderia ser um argumento contra nossos resultados. Entretanto, a motivação por trás do uso desse teste para a verificação de constituência é justamente a uniformidade de interface, que a SMS busca pôr sob suspeita. Veja-se, por exemplo, a sentença abaixo: Aline colocou o copo no armário e o garfo na gaveta.

Em GGT, poderia ser sugerido que o que é representado no nível subjacente a (73) é (73a):

(73a) Aline $e_{i}$ colocou o copo no armário e pro ${ }_{i}$ colocou o garfo na gaveta.

O que ocorre para gerar (73) é: (i) pro, por ser uma categoria vazia, não corresponde a material fonológico; e, (ii) na passagem para a estrutura superficial (ou no mapeamento para PF, dependendo do estágio da teoria), o segundo verbo é apagado. Toda essa explicação está calcada em um vocabulário teórico motivado (em larga medida) pela necessidade de tornar a interface uniforme (CULICOVER; JACKENDOFF, 2005, cap. 1). Na SMS, a explicação teria de ser outra, pois a teoria não prevê estruturas subjacentes, categorias vazias ou operações de apagamento: a sentença seria gerada na ordem da linearidade e não projetaria elementos fonologicamente nulos ou materiais elididos. A explicação para o modo como interpretamos (73) seria principalmente semântica: a conjunção coordena dois constituintes semanticamente completos e permite recuperar na semântica a proposição Aline colocou o garfo na gaveta.

\footnotetext{
[...] o que nós vemos no caso de NPs unidos pela conjunção é que as exigências semânticas à estrutura sintática são variáveis. A estrutura sintática é licenciada pela possível correspondência a uma EC [estrutura conceitual] bem-formada, e qualquer configuração sintática particular só será bem-formada se essa correspondência puder ser estabelecida. (CULICOVER; JACKENDOFF, 2005, p. 143)
}

Isso porque, segundo os autores, uma coordenação bem formada de NPs é uma conjunção bem formada na EC. A coordenação é, portanto, licenciada principalmente no nível semântico, não no sintático. Podemos estender essa conclusão para a coordenação de quaisquer elementos: se conseguimos coordenar dois elementos, isso significa que temos dois constituintes semânticos compatíveis, mesmo que eles correspondam a fragmentos sintáticos (cf. VARASCHIN, 2017). Esse seria especificamente o caso da possibilidade de coordenação de estruturas subpredicativas que não formam SCs. 
Ademais, como lembra Carnie (2007) - ainda dentro da GGT -, o teste da coordenação utilizado isoladamente não é muito seguro, uma vez que pode conduzir a falsos diagnósticos:

$$
\text { Aquele risoto, o Gabriel preparou e a Ana adorou. }
$$

O teste aplicado cegamente a essa sentença poderia levar à conclusão de que o Gabriel preparou é um sintagma. No entanto, sabemos que o verbo não forma isoladamente um constituinte com seu argumento externo. Nesse caso, a proposta tradicional é que o argumento interno é gerado, formando um sintagma com o verbo, e depois movido (ou apagado) em etapas derivacionais posteriores. Mas o teste da coordenação, por si só, não garante essa conclusão.

Levando em conta as objeções de Culicover e Jackendoff (2005) e de Carnie (2007), concluímos que o teste da coordenação não é confiável para aferir constituência sintática, especialmente dentro do quadro teórico da SMS. Além disso, ainda com base em Carnie (2007), poderíamos argumentar que, se cinco testes apontam em uma direção e apenas um teste aponta (aparentemente) no sentido oposto, é mais prudente seguir o resultado indicado pelo número maior de testes.

Como já mencionamos de passagem, outro teste proposto por Culicover e Jackendoff (2005) especificamente para testar a constituência de SCs é o do gerúndio: de acordo com os autores, só seria possível que a subpredicação ocorra através de um predicado gerundivo quando é formado um sintagma do tipo SC. Para realizar o diagnóstico, então, é preciso inserir um predicado na forma de gerúndio; se a sentença resultante for aceitável, é porque temos uma SC:

(75) Todos ouviram/viram/imaginaram João correndo pelas escadas.

(76) ? Todos julgaram/declararam/consideraram João correndo pelas escadas.

As sentenças em (76) não são aceitáveis na interpretação com subpredicação. Isso seria mais um indício de que esses verbos não selecionam uma SC como complemento. Entretanto, esse teste nos parece mais uma descrição de como se comportam as subpredicações com projeção sintática de SC do que um diagnóstico da formação desse constituinte.

Outra peculiaridade que, ao menos no $\mathrm{PB}$, distingue os verbos que licenciam SC dos outros é a possibilidade de selecionar um predicado no infinitivo:

(77) Todos ouviram/viram/(?) imaginaram João correr pelas escadas.

(78) ? Todos julgaram/declararam/consideraram João correr pelas escadas.

Culicover e Jackendoff (2005) chamam as estruturas de complemento de verbos do Grupo 2 (como o exemplo em (78)) de falsas SCs, pois elas se assemelham semanticamente às SCs, mas possuem estruturas sintáticas diferentes. Dizer que as estruturas licenciadas pelos dois grupos de verbos são diferentes e que suas representações semânticas são idênticas configura um abandono do princípio da uniformidade da interface entre sintaxe-semântica. Admite-se que estruturas sintáticas distintas podem convergir em um mesmo tipo de significado (no caso, a subpredicação) e que um mesmo significado pode ter expressões sintáticas distintas.

\section{CONSIDERAÇÕES FINAIS}

Este artigo baseou-se Sintaxe mais Simples de Culicover e Jackendoff(2005), uma teoria formal de gramática alternativa à GGT, que põe uma ênfase especial em questões de economia representacional, buscando simplificar e reduzir ao máximo as estruturas sintáticas geradas na língua. Na SMS, fonologia e semântica não são interpretadas a partir das estruturas de interface PF e LF, mas são concebidas como eixos estruturantes do sistema linguístico, gerados paralelamente à sintaxe. Ao contrário da GGT, a teoria é fortemente baseada em restrições e não envolve transformações (ou derivações). Mas, assim como a GGT, a SMS compreende a linguagem como um sistema gerativo, formalizável, inato, modular e mental. 
Um eixo que norteou a nossa discussão foi o que Culicover e Jackendoff denominam Princípio de Uniformidade entre sintaxe e semântica. Este princípio seria adotado em boa parte das análises em GGT, motivando muitas vezes estruturas sintáticas complexas. A proposta dos autores vai em um sentido contrário, pois na SMS a sintaxe deve compreender a estrutura mínima necessária para fazer a mediação entre fonologia e significado.

Com base nisso, analisamos o fenômeno semântico da subpredicação, definindo-o como uma predicação interna à outra. Como a GGT adota, em geral, o princípio da uniformidade, essa estrutura costuma ser uniformemente projetada na sintaxe como uma SC. Entretanto, por não assumirmos esse princípio como obrigatório, propusemos que o fenômeno da subpredicação só é projetado como SC quando há motivação empírica que indique a formação dessa estrutura. A fim de verificar empiricamente em quais casos a estrutura de predicação realmente corresponde a uma SC sintática, fizemos uma breve exposição sobre a concepção de sintagmas na SMS e aplicamos alguns testes de constituência reunidos por Haegeman (2006) a verbos que podem selecionar subpredicações em PB. Analisamos ao total 15 verbos e testamos quais desses verbos podem subcategorizar um constituinte do tipo SC como complemento.

A partir do resultado da aplicação dos testes de pronominalização, topicalização, pergunta-QU, pseudo-clivada e clivada, classificamos os verbos em dois grupos: aqueles que projetam a subpredicação por meio de um sintagma do tipo SC e aqueles que não o fazem. A análise de dados em PB, portanto, corrobora os resultados preliminares obtidos por Culicover e Jackendoff (2005): de fato, algumas estruturas semânticas de subpredicação parecem não formar um único constituinte sintático. Quando os testes indicaram que o verbo pode subcategorizar uma SC, ele foi projetado de forma semelhante ao que é tradicionalmente proposto: [vP $\mathrm{V}$ [sc XP YP]]. Nos casos em que não atestamos um sintagma SC, sugerimos que a projeção sintática da subpredicação é flat e ocorre da mesma forma como se representam os verbos triargumentais: em SMS, ramificando-se diretamente de VP: [vP V XP YP].

Com este artigo, esperamos ter conseguido mostrar que uma teoria sintática que abandona a uniformidade de interface como um princípio obrigatório consegue dar conta de explicar alguns fenômenos linguísticos de maneira mais econômica. Ao deixarmos de lado esse preceito, nossas análises sintáticas ficam mais flexíveis e torna-se possível postular maior complexidade estrutural apenas quando ela é empiricamente motivada.

\section{REFERÊNCIAS}

AUSTIN, J. L. How to do things with words. Cambridge: Harvard University Press, 1975 [1962].

BURZIO, L. Italian syntax: a government-binding approach. Dordrecht: D. Reidel Publishing Company, 1986.

CARDINALETTI, A.; GUASTI, M. T. Epistemic small clauses and null subjects. In.: WESTPHAL, G.; AO, B.; CHAE, H.-R. (org.). Proceedings of VII Eastern States Conference of Linguistics, Ohio State University Press: Columbus, 1992. p. 23-33.

CARDINALETTI, A.; GUASTI, M. T. Small clauses: some controversies and issues of acquisition. In: CARDINALETTI, A.; GUASTI, M. T. (org.). Syntax and semantics: small clauses (vol) 28. San Diego: Academic Press, 1995, p. 1-23.

CARNIE, A. Syntax: A Generative Introduction. 2. ed. Oxford: Blackwell Publishing, 2007.

CHOMSKY, N. A Minimalist program for linguistic theory. In: HALE, K.; KEYSER, S. J. (org.). The View from Building 20. Cambridge: MIT Press, 1993.p. 195-227.

CHOMSKY, N. Aspects of the theory of syntax. Cambridge: MIT Press, 1965.

CHOMSKY, N. Language and responsibility. New York: Pantheon Books, 1979. 
CHOMSKY, N. Lectures on government and binding. Dordrecht: Foris, 1981.

CHOMSKY, N. Minimalist inquiries: the framework. In: MARTIN, R.; MICHAELS, D.; URIAGEREKA, J. (org.). Step by Step: essays in honor of Howard Lasnik. Cambridge: MIT Press, 2000. p. 89-155.

CHOMSKY, N. Some notes on the economy of derivation and representation. In: FREIDIN, R. (org.). Principles and parameters in comparative grammar. Cambridge: MIT Press, 1991. p. 417-454.

CHOMSKY, N. Studies on semantics in generative Grammar. The Hague: Mouton, 1972.

CHOMSKY, N. Syntactic structures. The Hague: Mouton, 1957.

CHOMSKY, N. The minimalist program. Cambridge: MIT Press, 1995.

CHOMSKY, N.; BELLETTI, A.; RIZZI, L. Reflections on language. New York: Pantheon, 1975.

CINQUE, G. The pseudo-relative and ACC-ing constructions after verbs of perception. University of Venice, 1991.

CONTRERAS, H. Small clauses and complex predicates. In: CARDINALETTI, A.; GUASTI, M. T. (org.). Syntax and semantics: small clauses (vol) 28. San Diego: Academic Press, 1995. p. 135-152.

CULICOVER, P. Concrete minimalism, branching structure, and linear order. Proceedings of GLiP-2 (Generative Linguistics in Poland). Warsaw, 2000.

CULICOVER, P; JACKENDOFF, R. Simpler Syntax. New York: Oxford University Press, 2005.

FOLTRAN, M. J. As construções de predicação secundária no português do Brasil: aspectos sintáticos e semânticos. 1999. Tese (Doutorado em Linguística) - Universidade de São Paulo, São Paulo, 1999.

FOLTRAN, M. J. Predicados secundários: restrições semânticas. Revista Letras, Curitiba, n. 58, p. 211-223, jul./dez. 2002.

GOMES, A. F. R.; FOLTRAN, M. J. Small clause complemento: caracterização e seleção. Revista de Estudos da Linguagem, v. 17, n. 2, p. 51-71. jul./dez., 2009.

GUÉRON, J.; HOEKSTRA, T. The temporal interpretation of predication. In: CARDINALETTI, A.; GUASTI, M. T. (org.). Syntax and semantics: small clauses (vol) 28. San Diego: Academic Press, 1995. p. 77-107.

HAEGEMAN, L. Introduction to government and binding theory. Malden/Oxford: Blackwell Publishing, 1994.

HAEGEMAN, L. Thinking syntactically: a guide to argumentation and analysis. Cornwell: Blackwell Publishing, 2006.

JACKENDOFF, R. Foundations of language: Brain, meaning, grammar, evolution. New York: Oxford University Press, 2002.

JACKENDOFF, R. Language, consciousness, culture: Essays on mental structure. Cambridge: MIT Press, 2007.

KATO, M.; MIOTO, C. A arquitetura da gramática. In: KATO, M.; NASCIMENTO, M. do. (org.). Gramática do português culto falado no Brasil, vol 2: a construção da sentença. São Paulo: Contexto, 2015. p. 19-35.

LASNIK, H; DEPIANTE, M.; STEPANOV, A. Syntactic structures revisited: contemporary lectures on classic transformational theory. Cambridge: MIT Press, 2000. 
MILIORINI, R. As representações sintáticas da subpredicação em PB: a não-uniformidade entre forma e sentido. 2016. Dissertação (Mestrado em Linguística) - Programa de Pós-Graduação em Linguística, Universidade Federal de Santa Catarina, Florianópolis, 2016.

MILIORINI, R. O que cortar com a navalha: economia na Gramática Gerativa e na Sintaxe mais Simples. Revista do GELNE, Natal, v. 20, n. 1, p. 57-73, 2018.

MIOTO, C.; FIGUEIREDO SILVA, M. C.; LOPES, R. Novo manual de sintaxe. 3. ed. Florianópolis: Insular, 2007.

MIOTO, C.; FIGUEIREDO SILVA, M. C.; LOPES, R. Novo manual de sintaxe. São Paulo: Contexto, 2013.

MIOTO, C.; FOLTRAN, M. J. A favor de small clauses. Caderno de Estudos Linguísticos, Campinas, v. 49, n. 1, p. 11-28, 2007.

MORTARI, C. A. Introdução à lógica. São Paulo: Editora da Unesp, 2001.

MOURA, H. A linguagem não é transparente. Um estudo sobre a relação entre forma e sentido. Florianópolis: Ed. da UFSC, 2018.

PERLMUTTER, D. Impersonal passives and the Unaccusative Hypothesis. In: Proceedings of the 4th Annual Meeting of the Berkeley Linguistics Society, 1978. p. 157-190.

PROGOVAC, L. Evolutionary Syntax. New York: Oxford University Press, 2015.

PROGOVAC, L. The syntax of nonsententials: Small clauses and phrases at the root. In: PROGOVAC, L. et al. The syntax of nonsententials: multidisciplinary perspectives. Philadelphia: John Benjamins Publishing Company, 2006. p. 33-71.

RADFORD, A. Syntactic theory and the acquisition of English syntax. Oxford: Basil Blackwell, 1990.

RADFORD, A. Transformational grammar: A first course. Cambridge: Cambridge University Press, 1988.

RAPOSO, E; URIAGEREKA, J. Long distance case assignment. Linguistic Inquiry, Cambridge, v. 21, p. 505-537, 1990.

RAPOSO, E; URIAGEREKA, J. Two types of small clauses (toward a syntax of theme/rheme relations). In: CARDINALETTI, A.; GUASTI, M. T. (org.). Syntax and semantics: small clauses (vol) 28. San Diego: Academic Press, 1995. p. 179-206.

RODRIGUES, P. A. O status de small clauses das construções gerundivas e adjetivais complementos de verbos de percepção com interpretação imaginativa. In: ENCONTRO CELSUL - Círculo de Estudos Linguísticos do Sul, 6., Florianópolis, 2001. Anais... Florianópolis: UFSC, 2004.

ROTHSTEIN, S. Predicates and their subjects. Dordrecht: Kluwer Academic Publishers, 2001.

ROTHSTEIN, S. Small clauses and copular constructions. In: CARDINALETTI, A.; GUASTI, M. T. (org.). Syntax and semantics: small clauses (vol) 28. San Diego: Academic Press, 1995. p. 27-48.

SEARLE, J. Expression and meaning: studies in the theory of speech acts. New York: Cambridge University Press, 1979.

SEARLE, J. Speech acts: an essay in the philosophy of language. New York: Cambridge University Press, 1969.

STOWELL, T. Remarks on clause structure. In: CARDINALETTI, A.; GUASTI, M. T. (org.). Syntax and semantics: small clauses (vol) 28. San Diego: Academic Press, 1995. p. 271-286. 
STOWELL, T. Subjects across categories. The Linguistic Review 2. p. 285-312, 1983.

VARASCHIN, G. Uma análise cognitiva da conjunção proposicional: revisando a paradigma griceano. 2017. Dissertação (Mestrado em Linguística) - Programa de Pós-Graduação em Linguística, Universidade Federal de Santa Catarina, Florianópolis, 2017.

WILLIAMS, E. Against small clauses. Linguistic Inquiry, Cambridge, v. 14, n. 2, p. 287-308, 1983

WILLIAMS, E. Small clauses in English. In: KIMBALL, J. (org.). Syntax and semantics. (vol) 4. Orlando: Academic Press, 1975. p. $249-273$.

\section{()(1) $\circledast$}

Recebido em 31/03/2020. Aceito em 21/04/2020. 